\title{
TUTELA JUDICIAL EFECTIVA Y ESTADO DE DERECHO EN LA UE Y SU INCIDENCIA EN LA ADMINISTRACIÓN DE JUSTICIA DE LOS ESTADOS MIEMBROS
}

\author{
JUAN IGNACIO UGARTEMENDIA ECEIZABARRENA \\ Catedrático (A) de Derecho Constitucional \\ Universidad del País Vasco ${ }^{1}$
}

TRC, núm. 46, 2020, pp. 309-341

ISSN 1139-5583

\begin{abstract}
SUMARIO
I. Introducción. II. El reconocimiento de la tutela judicial efectiva en la Unión europea. III. El fortalecimiento de la dimensión objetiva de la tutela judicial efectiva en la Unión Europea. IV. La dimensión objetiva del derecho fundamental a la tutela judicial efectiva de la UE como parámetro de control de europeidad de las medidas nacionales relativas a la administración judicial V. Conclusiones
\end{abstract}

\section{INTRODUCCIÓN}

El objetivo de estas páginas consiste en describir que el reconocimiento de la tutela judicial efectiva que realiza el Derecho de la Unión Europea incide sobre la regulación nacional de la Administración de Justicia. No cabe duda de que la competencia para regular y actuar en materia relativa a la organización y funcionamiento judicial nacional es una competencia exclusivamente estatal, retenida y no transferida por los Estados. Sin embargo, desde hace un par de años, el Tribunal de Justicia está dando a entender que las medidas nacionales sobre la Administración judicial nacional no pueden ser contrarias a la regulación sobre la

1 Este trabajo ha sido realizado en el marco del Grupo de Investigación «GIC Derechos Fundamentales y Unión Europea», financiado por el Gobierno Vasco, así como del PI «La consolidación de la Carta de Derechos Fundamentales de la Unión Europea en su aplicación en los Estados miembros» (DER2017-89753-P). 
tutela o protección judicial tal y como ésta es reconocida por la Unión. Esa regulación europea actúa así como parámetro o canon de control de las medidas estatales. Precisando un poco más el fenómeno, es posible señalar que, en realidad, es la dimensión objetiva del derecho fundamental a la tutela judicial efectiva de la Unión la que funciona como ese parámetro de control.

Los derechos fundamentales tienen, como es conocido, una doble dimensión o vertiente: una subjetiva y otra objetiva o sistémica. En su vertiente subjetiva o personal, los derechos fundamentales son pretensiones, facultades o libertades que las personas pueden hacer valer en situaciones concretas (como la pretensión subjetiva de cada persona de recibir protección judicial de los derechos que le corresponden). Pero, por otra parte, y de forma no excluyente, sino más bien simultánea, los derechos fundamentales tienen asimismo una dimensión objetiva, pues encarnan u operan como valores básicos o elementos estructurales de la organización del poder y del orden constitucional, caracterizando el mismo. De ahí surge la existencia — más allá de cualquier situación jurídica concreta- de un «deber general de protección y promoción de los derechos fundamentales por parte de los poderes públicos». Un deber que se articula a través de diversos mecanismos, que van desde los cauces del control de constitucionalidad de las leyes hasta la obligación de interpretación conforme a los mismos ${ }^{2}$.

La dimensión objetiva, estructural o sistémica del derecho fundamental a la tutela judicial efectiva está directamente ligada a la existencia del Estado de Derecho, y, por ende, del resto de los derechos y valores del ordenamiento. Si falla esta dimensión, no sólo falla mi derecho subjetivo a la protección judicial en un caso concreto, sino que lo que desaparece es el Estado de Derecho y el sistema de la protección de los derechos. Pues bien, como decía, será esta dimensión objetiva del derecho fundamental a la tutela judicial reconocido en la Unión la que actúa como límite de las medidas nacionales relativas a la Administración de Justicia, y la que posibilita un control de europeidad sobre las mismas. En lo que sigue se mostrará sobre qué bases, en qué casos y con qué mecanismos se está dando este control de europeidad.

\section{EL RECONOCIMIENTO DE LA TUTELA JUDICIAL EFECTIVA EN LA UNIÓN EUROPEA}

El Derecho de la Unión Europea no reconoció el Derecho Fundamental a la tutela judicial efectiva hasta que comenzó a hacerlo el Tribunal de Justicia, afirmando que el respeto o la existencia de ese derecho es un principio general del

2 Cfr. L. Díez-Picazo, Sistema de derechos fundamentales, Civitas / Thomson Reuters, Madrid, 2013 (4. ${ }^{a}$ ed.), p. 20. El TC reconoce esta doble dimensión de los Derecho Fundamentales en SSTC como la 25/1981, 53/1985, 64/1988; 120/1990; 108/2008 o 65/2015, entre otras. 
Derecho comunitario/UE. Así ocurrió, por ejemplo, en los asuntos Jobnston ${ }^{3}$ o Heyens y otros ${ }^{4}$, antes de que se proclamara la Carta de Derechos Fundamentales de la Unión Europea (CDFUE, 2000); en $U p a^{5}$ o en $U n i b e t^{6}$, una vez proclamada ésta; o también, habiendo ya entrado en vigor (2009), por ejemplo, en Arango $^{7}$ o $\mathrm{Kadi}^{8}$. La Carta, como se ha tenido ocasión de apuntar, recogió y reafirmó este derecho en su artículo 47 («Derecho a la tutela judicial y a un juez imparcial»), cuyo primer párrafo dispone: «Toda persona cuyos derechos y libertades garantizados por el Derecho de la Unión hayan sido violados tiene derecho a la tutela judicial efectiva respetando las condiciones establecidas en el presente artículo» ${ }^{9}$.

Unido a ello el Tribunal ha venido afirmando que «incumbe a los órganos jurisdiccionales de los Estados miembros, en virtud del principio de cooperación establecido por el artículo $10 \mathrm{CE}$, proporcionar la tutela judicial de los derechos que el Derecho comunitario confiere a los justiciables ${ }^{10}$, y asimismo, que (ante la inexistencia de una normativa de la Unión en la materia) «corresponde al ordenamiento jurídico interno de cada Estado miembro designar los órganos jurisdiccionales competentes y configurar la regulación procesal de los recursos judiciales destinados a garantizar la salvaguardia de los derechos que el Derecho comunitario confiere a los justiciables» ${ }^{11}$. En esta misma línea, y en palabras más recientes, el Tribunal reiterará con cierta asiduidad que atañe a los Estados miembros «prever un sistema de vías de recurso y de

3 De 15 de mayo de 1986, donde se reconocía como tal principio general la existencia de un control jurisdiccional para invocar los derechos reconocidos por el ordenamiento comunitario ante los tribunales nacionales, así como el derecho a un recurso efectivo ante un órgano jurisdiccional (ap. 18 y 19).

4 De 15 de octubre de 1987, reconociendo la exigencia de una vía de recurso de carácter jurisdiccional como un principio general del Derecho comunitario (ap. 14 y 15).

5 Unión de Pequeños Agricultores/Consejo, de 25 de julio de 2002. Sentencia en la que se señalaba que «los particulares deben poder disfrutar de una tutela judicial efectiva de los derechos que les confiere el ordenamiento jurídico comunitario, ya que el derecho a dicha tutela forma parte de los principios generales del Derecho que resultan de las tradiciones constitucionales comunes a los Estados miembros. Este derecho también ha sido consagrado en los artículos 6 y 13 del Convenio Europeo par a la Protección de los Derechos Humanos y de las Libertades Fundamentales» (ap. 39)

6 De 13 de marzo de 2007, ap. 37.

7 De 28 de febrero de 2013, apartado 40.

8 De 18 de julio de 2013, ap. 97 y ss.; véase, también, Deutsche Lufthansa SA, de 21 de noviembre de 2019, ap. 56 y ss.; o Comisión/Polonia, de 5 de noviembre de 2019, ap. 100 (y jurisprudencia allí citada).

9 El cual continúa afirmando, en su segundo y tercer párrafo: «Toda persona tiene derecho a que su causa sea oída equitativa y públicamente y dentro de un plazo razonable por un juez independiente e imparcial, establecido previamente por la ley. Toda persona podrá hacerse aconsejar, defender y representar. // Se prestará asistencia jurídica gratuita a quienes no dispongan de recursos suficientes siempre y cuando dicha asistencia sea necesaria para garantizar la efectividad del acceso a la justicia».

10 SSTJ: Rewe, de 16 de diciembre de 1976, ap. 5; Simmenthal, de 9 de marzo de 1978, ap. 21 y 22; Factortame y otros, de 19 de junio de 1990, ap. 19; Peterbroeck, de 14 de diciembre de 1995, ap. 12; Unibet, cit., ap. 38. Se trata de una tutela que, como señala la mencionada jurisprudencia $R E W E$, debe ser acorde con los principios de equivalencia y efectividad. Sobre el reconocimiento de la tutela judicial efectiva en el Derecho de la Unión Europea y su evolución, por ejemplo: M. BonELli, «Effective Judicial Protection in EU Law: an Evolving Principle of a Constitutional Nature», Review of European Administrative Law, 12, 2, pp. 37 y ss.

11 SSTJ: Rewe, cit., ap. 5; Peterbroeck, cit., ap. 12; Safalero, de 11 de septiembre de 2003, ap. 49; o Unibet, cit., ap. 39. 
procedimientos que permita garantizar el respeto del derecho fundamental a la tutela judicial efectiva» ${ }^{12}$. Y será esta idea crucial, plasmada jurisprudencialmente, la que se verá luego así recogida, en el ya mencionado 19.1 (2) TUE, a través de la reforma del Tratado de Lisboa. Esta reforma, aprobada en 2007 y que entró en vigor en diciembre del año 2009, será también importante, además, porque reconoció al «Estado de Derecho» como uno de los valores en los que se fundamenta la Unión en el art. 2 del TUE (sin perjuicio de la existencia de referencias previas al mismo, por ejemplo, en los Preámbulos del TUE y de la $\left.\mathrm{Carta}^{13}\right)$.

\section{EL FORTALECIMIENTO DE LA DIMENSIÓN OBJETIVA DE LA TUTELA JUDICIAL EFECTIVA EN LA UNIÓN EUROPEA}

Llegados aquí, es importante resaltar que, desde hace dos años, se está produciendo un nuevo y notable paso en el reconocimiento del derecho fundamental a la tutela judicial efectiva en la Unión Europea. Este paso consiste, podríamos denominarlo así ahora, en un fortalecimiento de su dimensión objetiva, sistémica o estructural, la cual se manifiesta, dicho de forma muy esquemática, en la conexión de la tutela judicial efectiva con el valor Estado de Derecho, con la independencia judicial como exigencia primordial del mismo ${ }^{14}$. Una dimensión que se puede hacer valer frente a medidas o disposiciones nacionales que se oponen a misma.

Ese fortalecimiento se ha forjado a través de una serie de Sentencias del TJ, que comienza en 2018 con la Sentencia Asociación Sindical de Jueces Portugueses (o ASJP) ${ }^{15}$, y continúa, principalmente, con otras cuatro sentencias que forman su progenie jurisprudencial: Minister for Justice and Equality ${ }^{16}$, dos sentencias recaídas en sendos procedimientos por incumplimiento contra la República de Polonia (Comisión/ Polonia $)^{17}$ y A.K. y otros ${ }^{18}$; resoluciones sobre las que volveremos más adelante.

12 UPA, cit., ap. 41; Comisión/Jégo/Quéré, 1 de abril de 2004, ap. 31; o Inuit Tapiriit Kanatami, de 3 de octubre de 2013, ap. 100.

13 O de que la STJCE Partie Ecologiste 'Les Verts' V Parlamento Europeo (de 23 de abril de 1986) ya caracterizaba a la Comunidad Económica Europea como «a Community based on the rule of law» [ap.23; véase también el Dictamen 1/91 del TJCE, de 14 de diciembre de 1991, en el que se afirmaba que el Tratado de la CEE «constitutes the constitutional charter of a Community based on the rule of law» (ap. 21)].

14 Sobre el hecho de que la tutela judicial efectiva, además de operar como un principio procesal, ha ido adquiriendo un carácter de principio sustantivo y estructural, de amplia relevancia constitucional, véase: M. Bonelli, «Effective Judicial Protection in EU Law..», op. cit., pp. 35 y ss. y 45 y ss.

15 Associação Sindical dos Juizes Portugueses contra Tribunal de Contas, de 27 de junio de 2018. En todo caso, puede considerarse que existen algunos indicios del contenido de esta jurisprudencia en cuanto a la tutela judicial efectiva en SSTJ previas como: Rosneft (de 28 de marzo de 2017, ap. 75 y ss.) o Achmea (de 6 de marzo de 2018, ap. 36 o 55).

16 También conocida como $L M$, de 25 de julio de 2018.

17 Comisión/Polonia, de 24 de junio de 2019 (C-619/18) y Comisión/Polonia, de 5 de noviembre de 2019 (C-192/18).

18 De 19 de noviembre de 2019. 
Dichas resoluciones recuerdan que el derecho fundamental a la tutela judicial efectiva de los derechos que el ordenamiento jurídico de la Unión confiere a los justiciables, es un principio general del Derecho de la Unión que emana de las tradiciones constitucionales comunes a los Estados miembros, que ha sido también consagrado en los artículos 6 y 13 del Convenio Europeo de Derechos Humanos, y que en la actualidad se reconoce en el mencionado artículo 47 de la Carta. Pero enfatizan, asimismo, siendo esta la constatación que comienza ahora a adquirir un notable protagonismo, que es también un principio que aparece referido en el segundo párrafo del artículo 19.1 del TUE, cuando se dispone que: «los Estados miembros establecerán las vías de recurso necesarias para garantizar la tutela judicial efectiva en los ámbitos cubiertos por el Derecho de la Unión ${ }^{19}$. Previamente, interesa también recalcarlo ahora, el primer apartado del citado artículo habrá dispuesto que el Tribunal de Justicia de la Unión Europea ${ }^{20}$ «garantizará el respeto del Derecho en la interpretación y aplicación de los Tratados» ${ }^{21}$.

A través de esta saga o serie jurisprudencial el Tribunal desarrolla y repite una «secuencia argumental» formada por tres ideas o elementos, la cual — de una manera u otra- aparece en todas las Sentencias, y tiene como efecto el mencionado fortalecimiento. La primera idea consiste en que la misión de garantizar el control judicial en el ordenamiento jurídico de la Unión es una misión o encomienda que corresponde, también, al «Juez nacional»; en segundo lugar, la existencia de un vínculo inseparable entre la tutela judicial efectiva y el «Estado de Derecho»; y finalmente, que los órganos jurisdiccionales nacionales que actúan en ámbitos cubiertos por el Derecho de la UE deben cumplir con las exigencias de la tutela judicial, entre los que el Tribunal destaca ahora la independencia judicial. Las tres ideas, conectadas entre sí, están basadas —aunque no sólo- en el art. 19.1(2) TUE.

\section{El Juez nacional como garante del control judicial en el ordenamiento jurídico de la Unión}

La primera idea o elemento de la secuencia argumental consiste en que, según señala ahora el TJ, el art. 19 TUE «atribuye el cometido de garantizar el control judicial en el ordenamiento jurídico de la Unión no sólo al Tribunal de Justicia,

19 Plasmando, como se ha dicho, sólo implícitamente el crucial papel que desempeña el juez nacional en el entramado jurisdiccional europeo (R. Alonso García, Sistema jurídico de la Unión Europea, Civitas / Thomson Reuters, Madrid, 2014, p. 203).

20 La institución «Tribunal de Justicia de la Unión Europea» (TJUE) comprendida por los órganos «Tribunal de Justicia» (TJ), «Tribunal General» (TG) y los «tribunales especializados».

21 El art. 19.2 especificará la composición del TJ y del TG, así como reglas sobe la elección de los jueces que los componen y los abogados generales que asisten al primero. El tercer apartado, por su parte, está referido a las cuestiones sobre las que compete pronunciarse al TJUE. 
sino también a los tribunales nacionales $»^{22}$. Estos tribunales deben desempeñar «en colaboración» con el TJ la función, que se le ha atribuido en común con dicho Tribunal, de «garantizar el cumplimiento del Derecho en la interpretación y en la aplicación de los Tratados» ${ }^{23}$. Incumbe, en otras palabras, a esos «órganos jurisdiccionales nacionales y al Tribunal de Justicia garantizar la plena aplicación del Derecho de la Unión en el conjunto de los Estados miembros y la tutela judicial de los derechos que ese ordenamiento jurídico confiere a los justiciables» ${ }^{24}$.

Y son los Estados miembros los que deben prever un sistema de vías de recurso y de procedimientos adecuado para garantizar ese control y esa tutela judicial efectiva en los ámbitos cubiertos por el Derecho de la Unión [una idea ésta que ya venía siendo reconocida — como hemos visto - en la jurisprudencia inicial sobre este derecho, y es confirmada, asimismo, en resoluciones posteriores a su incorporación en el 19.1 (2) TUE por la reforma de Lisboa ${ }^{25}$, artículo en el que aparece reflejada].

\section{El vínculo inseparable entre la tutela judicial efectiva y el «Estado de Derecho»}

El Tribunal de Justicia conecta reiteradamente la interpretación de la tutela judicial efectiva del art. 19.1 (2) TUE y —en menor medida- del 47 de la CDFUE con la afirmación del valor «Estado de Derecho» reconocido en el art. 2

22 ASJP, cit., ap. 32 [citando, a su vez, su Dictamen 1/09 (Acuerdo por el que se crea un Sistema Unificado de Resolución de Litigios sobre Patentes), de 8 de marzo de 2011, ap. 66; y las Sentencias: Inuit Tapiriit Kanatami, cit., ap. 90, y $T$ E L SUGARS, de 28 de abril de 2015, ap. 45]. Véase también, al respecto, por ejemplo: M. Campos SÁnchez-Bordona, «La protección de la independencia judicial en el derecho de la Unión Europea», RDCE, 65, 2020, p. 12. Como contrapunto, puede ser interesante recordar que el Abogado General Henrik Saugmandsgaard ØE mantenía una opinión contraria al respecto en sus Conclusiones al asunto ASJP, de 17 de mayo de 2017, cuando señalaba que el párrafo segundo del art. 19.1 «no se refiere directamente a los jueces nacionales, sino que pretende garantizar que existan posibilidades de recurso en los Estados miembros para que cada justiciable pueda beneficiarse de tal protección en todos los ámbitos en los que el Derecho de la Unión sea aplicable. Esta exigencia guarda relación con el hecho de que el control jurisdiccional del respeto del ordenamiento jurídico de la UE no solo lo garantizan sus propios órganos jurisdiccionales, sino que también se garantiza mediante la cooperación con los órganos jurisdiccionales nacionales, con arreglo a los dos párrafos de dicho apartado» (ap. 61; énfasis añadido). ap. 99).

23 ASJP, cit., ap. 33 (citando, a su vez, su Dictamen 1/09, cit., ap. 69; y la Inuit Tapiriit Kanatami, cit.,

24 STJ Minister for Justice, cit., ap. 50 [citando, a su vez, la ya señalada ASJP, cit., ap. 32, y la STJ Achmea, cit., ap. 36); también en: Comisión/Polonia (C-619/18), cit., ap. 47; Comisión/Polonia (C-192/18), cit., ap. 98; A.K. y otros, cit., ap. 167; o el Auto del TJ en el procedimiento de medidas provisionales en el as. Comisión/ Polonia, de 8 de abril de 2020, ap. 30.

25 Cfr. SSTJ: Inuit Tapiriit Kanatami, cit., ap. 100 y 101; ASJP, cit., ap. 34; Comisión/Polonia (C-619/18), cit., ap. 48; Comisión/Polonia (C-192/18), cit., ap. 99; Miasto Łowicz, de 26 de marzo de 2020, ap. 32; o ATJ Comisión/Polonia (C-791/19 R), cit., ap. 30. En la STJ A.K. y otros (cit.), sin embargo, liga también esta cuestión con el art. 47 de la CDFUE, recordando que incumbe a los Estados Miembros «la responsabilidad de garantizar, en cada caso, la observancia del derecho a la tutela judicial efectiva de dichos derechos como esta se garantiza en el artículo 47 de la Carta» (mencionando sus previas SSTJ: IN.CO.GE.'90 y otros, de 22 de octubre de 1998, ap. 14; Impact, de 15 de abril de 2008, ap. 44 y 45; y E.ON Földgáz Trade, de 19 de marzo de 2015, ap. 49 y 50, ap. 115). 
$\mathrm{TUE}^{26}$. Una vez recordado que, según dicho artículo, la Unión Europea «se fundamenta en valores, tales como el Estado de Derecho, que son comunes a los Estados miembros en una sociedad caracterizada, entre otras cosas, por la justicia» ${ }^{27}$, y que esa Unión es «una Unión de Derecho en la que los justiciables tienen derecho a impugnar judicialmente la legalidad de cualquier resolución o de cualquier otro acto nacional por los que se les aplique un acto de la propia Unión» ${ }^{28}$, el TJ afirmará, en cada una de las sentencias mencionadas, que lo que hace el artículo 19 TUE es referirse «con mayor concreción al valor de Estado de Derecho proclamado en el artículo 2 TUE» ${ }^{29}$. E insistirá, asimismo, en la idea de que «la existencia misma de un control judicial efectivo para garantizar el cumplimiento del Derecho de la Unión [que, como se ha visto, está ligada al citado artículo] es inherente a un Estado de Derecho» ${ }^{30}$. No existe Estado de Derecho sin tutela judicial efectiva, la cual, en la Unión Europea, por lo que a los ámbitos cubiertos por el Derecho de la Unión se refiere, corresponde garantizar también a los órganos jurisdiccionales nacionales.

Será, precisamente, esta conexión entre la tutela judicial efectiva y el Estado de Derecho, que, como veremos a continuación, aparece inescindiblemente asociada a

26 Cfr. M. Campos Sánchez-Bordona, «La protección de la independencia judicial...», op. cit., p. 12; M.J. García-Valdecasas Dorrego, «El Tribunal de Justicia, centinela de la independencia judicial desde la sentencia Associação Sindical dos Juizes Portugueses (ASJP)», REDE, 72, 2019, punto III.3. Sobre la asociación del art. 2 con otras disposiciones del TUE — como el relativo a la tutela judicial efectiva— generando un efecto de «amplificación mutua» de las disposiciones combinadas: A. VON Bogdandy y L.D. SPIEKER, «Contra los jueces que silencian las críticas. Los valores del artículo 2 TUE. Reverse Solange y las responsabilidades de los jueces nacionales», en A. Von Bogdandy, J.I. Ugartemendia, D. Sarmiento y Morales, M., El futuro de la Unión Europea. Retos y desafíos, IVAP/MPIL, Oñate (en edición), punto II.1 in fine y 2; de los mismos autores: «Countering the Judicial Silencing of Critics: Article 2 TEU Values, Reverse Solange, and the Responsibilities of National Judges», European Constitutional Law Review, 15, 3, 2019, pp. 391 y ss.

Según dispone el art. 2: «La Unión se fundamenta en los valores de respeto de la dignidad humana, libertad, democracia, igualdad, Estado de Derecho y respeto de los derechos humanos, incluidos los derechos de las personas pertenecientes a minorías. Estos valores son comunes a los Estados miembros en una sociedad caracterizada por el pluralismo, la no discriminación, la tolerancia, la justicia, la solidaridad y la igualdad entre mujeres y hombres». Para un análisis del citado artículo, particularmente del valor Estado de Derecho, y de su carácter normativo y justiciable, véanse, entre otros muchos: J. MARTín y PÉrez De NANCLARES, «La Unión Europea como comunidad de valores: a vueltas con la crisis de la democracia y del Estado de Derecho, TRC, 43, 2019, pp. 121-159; L.D. SpIEKER, Breathing Life into the Union's Common Values: On the Judicial Application of Article 2 TEU in the EU Value Crisis, German Law Journal, 20, 2019, pp. 1182-1213; A. VON Bogdandy y L.D. SPIEKER, «Contra los jueces que silencian las críticas...», op. cit.; del primero, también: «Ways to Frame the European Rule of Law: Rechtsgemeinschaft, Trust, Revolution, and Kantian Peace», European Constitutional Law Review 14, 2018, 675-699.

27 STJ ASJP, cit., ap. 30.

28 SSTJ: ASJP, cit., ap. 31; Minister for Justice, cit., ap. 49.

29 SSTJ: ASJP, cit., ap. 32 (énfasis añadido); Minister for Justice, cit., ap. 50; Comisión/Polonia (C-619/18), cit., ap. 47; Comisión/Polonia (C-192/18), cit., ap. 98; A.K. y otros, cit., ap. 167; o ATJ Comisión/Polonia (C-791/19 R), cit., ap. 32. Véase sobre el tema, por ejemplo: J.M. CorTÉs MARTín, «Sorteando los inconvenientes del artículo 7 TUE: el advenimiento del control jurisdiccional del Estado de derecho», RDCE, 66, 2020, pp. 473 y ss., espec. 487 y ss.

30 SSTJ: ASJP, cit., ap. 36 (recordando la previa STJ Rosneft, cit., ap. 73); Minister for Justice, cit., ap. 51; o A.K. y otros, cit., ap. 114. 
la independencia judicial ${ }^{31}$, la que conforma la dimensión objetiva o estructural del DF a la tutela judicial efectiva de la que venimos hablando. Como destaca también la Comisión Europea, «el núcleo del estado de derecho es la protección judicial efectiva, que requiere la independencia, calidad y eficiencia de los sistemas de justicia nacionales» ${ }^{32}$. Ahora bien, y antes de centrarnos en la cuestión de la independencia judicial, resulta de interés destacar también, siquiera de forma breve, que este valor Estado de Derecho, cuyo núcleo es la tutela judicial efectiva, aun siendo un valor en sí mismo, responde también a la consecución de otros objetivos o fines.

La Comisión Europea resalta muy significativamente que el valor Estado de Derecho consagrado en el art. 2 TUE, «es un requisito previo para la protección de todos los demás valores fundamentales de la Unión, incluidos los derechos fundamentales y la democracia», y que su respeto «es esencial para el funcionamiento mismo de la UE: para la aplicación efectiva del derecho de la UE, para el funcionamiento adecuado del mercado interior, [y] para mantener un entorno favorable a la inversión y para la confianza mutua» ${ }^{33}$.

El propio Tribunal de Justicia viene a resaltar en esta jurisprudencia que «la confianza mutua entre los Estados miembros —y, en particular, entre sus juzgados y tribunales respectivos - se basa en la premisa fundamental de que los Estados miembros comparten una serie de valores comunes en los que se fundamenta la Unión, como se precisa en el propio artículo 2 TUE $»^{34}$. Y en esta misma línea, que, «tanto el principio de confianza mutua entre los Estados miembros como el principio de reconocimiento mutuo, que se basa a su vez en la confianza recíproca entre aquellos $\left.{ }^{35}\right]$, tienen una importancia fundamental en el Derecho de la Unión, dado que

31 Como señala el TJ: «La necesidad de independencia de los tribunales, inherente a la función jurisdiccional, está integrada en el contenido esencial del derecho a la tutela judicial efectiva y del derecho a un proceso equitativo, que reviste una importancia capital como garante de la protección del conjunto de los derechos que el Derecho de la Unión confiere a los justiciables y de la salvaguarda de los valores comunes de los Estados miembros proclamados en el artículo 2 TUE, en particular el valor del Estado de Derecho» [STJ Comisión/Polonia (C-192/18), cit., ap. 106; recordando sus previas SSTJ: Minister for Justice and Equality, cit., ap. 48 y 63; Comisión/Polonia (C-619/18), cit., ap. 58]; A.K. y otros, cit., ap. 120 y 124.

32 Dentro de su web, encabezando la sección Upholding the Rule of Law (dedicada a las iniciativas, actuaciones, comunicaciones, etc. de la Comisión para la defensa del «Rule of Law», en la que se aportan también datos y marcadores comparativos sobre la independencia, calidad y eficacia de los sistemas judiciales nacionales: el EU Justice Scoreboard; etc.): https:/ec.europa.eu/info/policies/justice-and-fundamental-rights/ upholding-rule-law_en

33 Upholding the Rule of Law, ibidem.

34 SSTJ: ASJP, cit., ap. 30 [citando, en este sentido, su previo Dictamen 2/13 sobre la Adhesión de la Unión Europea al CEDH, de 18 de diciembre de 2014, ap. 168] énfasis añadido; Minister for Justice, cit., ap. 35 (citando su previa STJ Achmea, cit., ap. 34); Comisión/Polonia (C-619/18), cit., ap. 42 [aludiendo a su previa STJ Wightman y otros, de 10 de diciembre de 2018, ap. 63 (en la que la mencionada idea se vincula con el dato de que, «como se desprende del artículo 49 TUE, que prevé la posibilidad de que cualquier Estado europeo solicite el ingreso como miembro de la Unión, ésta se compone de Estados que se han adherido libre y voluntariamente a los valores comunes proclamados en el artículo 2 TUE, los respetan y se comprometen a promoverlos»)].

35 Recordando, en este sentido, la sentencia de 10 de agosto de 2017, Tupikas, ap. 49 y jurisprudencia citada. 
permiten la creación y el mantenimiento de un espacio sin fronteras interiores ${ }^{36}$. Y no faltan tampoco los estudios doctrinales en los que se constata que la protección judicial efectiva constituye una «expresión concreta del principio de eficacia del Derecho de la Unión Europea» ${ }^{37}$, o aquellos en los que se afirma que el Tribunal utiliza el valor constitucional de la UE de respeto al estado de derecho como punto de referencia para afirmar su propia jurisdicción ${ }^{38}$.

\section{La independencia judicial como exigencia primordial entre los requisitos de la tutela judicial efectiva en la UE que debe cumplir un «órgano jurisdiccional»}

Según destaca de forma insistente el TJ, «todo Estado miembro debe garantizar concretamente, en virtud del artículo 19 TUE, apartado 1, párrafo segundo, que aquellos órganos que, en calidad de «órganos jurisdiccionales» —en el sentido definido por el ordenamiento jurídico de la Unión—, formen parte de su sistema de vías de recurso en los ámbitos cubiertos por el Derecho de la Unión, y que por lo tanto puedan tener que resolver, en tal calidad, sobre la aplicación o la interpretación del Derecho de la Unión, cumplan las exigencias de la tutela judicial efectiva» ${ }^{39}$.

Conviene señalar, antes de nada, que el Tribunal se está refiriendo a la idea de «órgano jurisdiccional» en el sentido definido por el Derecho de la Unión, para lo cual exige que se cumplan una serie de requisitos. A saber: «el origen legal del órgano, el carácter permanente del mismo, la obligatoriedad de su jurisdicción, la naturaleza contradictoria del procedimiento y la aplicación de normas jurídicas por parte del órgano, así como la independencia de éste ${ }^{40}$. Se trata, como podrá observarse, de los mismos requisitos que, según reiterada jurisprudencia del propio Tribunal de Justicia, se vienen requiriendo para poder dilucidar si un órgano nacional

36 STJ Minister for Justice, cit., ap. 36.

37 Sobre ello: P. Zinonos, «Judicial Independence \& National Judges in the Recent Case Law of the Court of Justice», European Public Law, 4, 2019, pp. 623 y ss. o 626 [trayendo a colación la idea articulada por la Abogada General J. Kokott, de que el principio de tutela judicial efectiva (en cuanto exigencia de que los derechos conferidos por el Derecho comunitario puedan ser ejercitados ante los tribunales) es «una manifestación concreta del principio de efectividad» (Conclusiones al as. Mellor, de 22 de enero de 2009).

38 P. Van Elsuwege y F. Gremmelprez, «Protecting the Rule of Law in the EU Legal Order: A Constitutional Role for the Court of Justice», European Constitutional Law Review, 16, 2020, p. 10. Dichos autores mostrarán que el respeto del Estado de Derecho ya venía desempeñando un papel importante en la jurisprudencia del Tribunal, mucho antes de que el concepto se mencionara explícitamente en los Tratados de la UE (sobre la base de las tradiciones constitucionales comunes de los Estados miembros); y que el Tratado de Lisboa propiciará que se refuerce ostensiblemente el papel constitucional que juega el mismo como piedra angular del ordenamiento jurídico de la UE (pp. 11 y ss.).

39 SSTJ: Comisión/Polonia (C-192/18), cit., ap. 103 (énfasis añadido); ASJP, cit., ap. 37; Minister for Justice, cit., ap., ap. 52.; Comisión/Polonia (C-619/18), cit., ap. 55; ATJ Comisión/Polonia (C-791/19 R), cit., ap. 31. 40 ASJP, cit., ap. 38. 
tiene la condición de «órgano jurisdiccional» a efectos de plantear la cuestión prejudicial del artículo 267 TFUE $^{41}$.

Hecha la descripción previa, el Tribunal resaltará que, entre las exigencias para garantizar la tutela judicial efectiva (las cuales no enumera), «resulta primordial preservar la independencia judicial de tal órgano» ${ }^{42}$. Afirma, en este sentido, que este requisito de la independencia judicial es una garantía «inherente a la misión de juzgar», la cual «no sólo se impone, en el ámbito de la Unión, en lo que respecta a los jueces y abogados generales del Tribunal de Justicia y a los jueces del Tribunal General, tal como prevé el artículo 19 TUE, apartado 2, párrafo tercero, sino que también obliga, en el ámbito de los Estados miembros, en lo que respecta a los jueces y tribunales nacionales ${ }^{43}$. Una exigencia de independencia de los órganos judiciales nacionales, basada en el art. 19.1 TUE ${ }^{44}$, que «resulta esencial» e imprescindible, asimismo, para el buen funcionamiento del sistema de cooperación judicial ínsito en el mecanismo de remisión prejudicial previsto en el artículo 267 TFUE $^{45}$.

Llegados aquí, el TJ recordará, una y otra vez, la interrelación existente entre la independencia judicial, la tutela judicial efectiva y el Estado de Derecho, tres

41 En este sentido, por ejemplo, las SSTJ: Syfait y otros, de 31 de mayo de 2005, ap. 29; Torresi, de 17 de julio de 2014, ap. 17; Consorci Sanitari del Maresme, de 6 de octubre de 2015, ap.17; Panicello, de 16 de febrero de 2017, ap. 27; Banco de Santander S.A., de 21 de enero de 2020, ap. 51.

42 ASJP, cit., ap. 41; Minister for Justice, cit., ap. 52 y 53; Comisión/Polonia (C-619/18), cit., ap. 57; Comisión/Polonia (C-192/18), cit., ap. 105.

El Tribunal no enumera ni señala cuáles son las otras exigencias, pero, partiendo del nexo de que el principio de tutela judicial efectiva de los derechos de las personas en el ámbito de la UE al que se refiere el art. 19.1(2) es un principio general del Derecho de la Unión derivado de las tradiciones constitucionales comunes a los Estados Miembros, consagrado también en los artículos 6 y 13 del CEDH, que está en la actualidad reconocido en el art. 47 CDFUE, L. Pech y S. Platon entienden que el concepto de «tutela judicial efectiva» del segundo párrafo del art. 19.1 abarca también otras garantías (exigencias), y en particular las enumeradas por los artículos 6-13 del CEDH y el artículo 47 de la Carta. A saber: el derecho a un juicio justo, a la audiencia pública, a ser juzgado dentro de un plazo razonable, por un Tribunal imparcial establecido previamente por ley, el derecho a ser aconsejado, defendido y representado, a la asistencia jurídica, etc. Ahora bien, la utilidad de dicho artículo para estas otras garantías sería probablemente menor que el desplegado con la independencia, por ser menos probable que las mismas se vean afectadas por medidas generales («Judicial Independence under threat: The Court of Justice to the rescue in the ASJP case», Common Market Law Review, 55, 6, 2018, pp. 12-13). En línea similar, en razón de los diversos contenidos del derecho a la tutela judicial efectiva contenidos en el art. 47 CDFUE y de la conexión de éste con el art. 19.1(2) TUE: A. Torres, «From Portugal to Poland: The Court of Justice of the European Union as watchdog of judicial independence», Maastricht Journal of European and Comparative Law, 6, 2020, pp. 111-112. Sobre las irregularidades que se estarían dando en Polonia en relación con el derecho a un recurso efectivo ante un tribunal independiente «previamente establecido por ley» véase: L. PECH, «Dealing with 'fake judges' under EU Law: Poland as a Case Study in light of the Court of Justice's ruling of 26 March 2020 in Simpson and HG», Reconnect, Working Paper n. ${ }^{\circ}$ 8, May. 2020, www.reconnect-europe.eu; J.M. CoRTÉs MARTín, «Sorteando los inconvenientes del artículo 7 TUE..., op. cit., pp. 497 y ss.

43 SSTJ: ASJP, cit., ap. 42; Escribano Vindel, de 7 de febrero de 2019, ap. 65.

44 R. Bustos Gisbert señalará que el uso del art. 19 TUE en cuestiones de independencia «constituye una novedad radical en el case Law de Luxemburgo", convirtiéndose «en el punto de apoyo que va a permitir la revolución» iniciada por la STJ ASJP y la serie jurisprudencial derivada de la misma («Comunicación transjudicial en Europa en defensa de la independencia de los jueces», ReDCE, 33, 2020, p. 17).

45 ASJP, cit., ap. 43; Minister for Justice, cit., ap. 54; Miasto Łowicz, cit., ap. 59. Sobre el tema, por ejemplo: P. Zinonos, «Judicial Independence \& National Judges...», op. cit., pp. 620-621. 
exigencias conexas e interdependientes. De forma más concreta, afirmará que «la necesidad de independencia de los tribunales, inherente a la función jurisdiccional, está integrada en el contenido esencial del derecho a la tutela judicial efectiva y del derecho a un proceso equitativo, que reviste una importancia capital como garante de la protección del conjunto de los derechos que el Derecho de la Unión confiere a los justiciables y de la salvaguarda de los valores comunes de los Estados miembros proclamados en el artículo 2 TUE, en particular el valor del Estado de Derecho» ${ }^{46}$.

Centrado ya en identificar su contenido, el Tribunal se esmera en detallar que la «exigencia de independencia» de los órganos jurisdiccionales, cuya observancia —en virtud del art. 19.1(2) — compete garantizar a los Estados miembros ${ }^{47}$, engloba dos aspectos. El primero, «de orden externo, supone que el órgano en cuestión ejerza sus funciones con plena autonomía, sin estar sometido a ningún vínculo jerárquico o de subordinación respecto a terceros y sin recibir órdenes ni instrucciones de ningún tipo, cualquiera que sea su procedencia, de tal modo que quede protegido de injerencias o presiones externas que puedan hacer peligrar la independencia de sus miembros a la hora de juzgar o que puedan influir en sus decisiones» ${ }^{48}$. Recuerda, asimismo, que la «inamovilidad judicial» constituye una garantía inherente a la independencia judicial en su dimensión externa, idónea para «proteger la persona de quienes tienen la misión de juzgar» ${ }^{49}$. El segundo aspecto, de orden interno, «se asocia por su parte al concepto de imparcialidad y se refiere a la equidistancia que debe guardar el órgano de que se trate con respecto a las partes del litigio y a sus intereses respectivos en relación con el objeto de dicho litigio. Este aspecto exige el respeto de la objetividad y la inexistencia de cualquier interés en la solución del litigio que no sea el de la aplicación estricta de la norma jurídica» ${ }^{50}$.

En cualquier caso, ambos órdenes o dimensiones, se concretan, para el Tribunal, en la existencia de unas reglas, «especialmente en lo referente a la composición del órgano, así como al nombramiento, a la duración del mandato y a las causas de inhibición, recusación y cese de sus miembros, que permitan excluir toda duda legítima en el ánimo de los justiciables en lo que respecta a la impermeabilidad de dicho órgano frente a elementos externos y en lo que respecta a su neutralidad con respecto a los intereses en litigio» ${ }^{51}$. Y lo mismo viene a señalar

46 Comisión/Polonia (C-619/18), cit., ap. 58; Minister for Justice, cit., ap. 48 y 63; Comisión/Polonia (C-192/18), cit., ap. 106; A.K. y otros, cit., ap. 120.

47 Por ejemplo: Comisión/Polonia (C-619/18), cit., ap. 71.

48 SSTJ: Minister for Justice, cit., ap. 63 (siguiendo lo ya señalado en la STJ ASJP, cit., ap. 44) énfasis añadido; Comisión/Polonia (C-619/18), cit., ap. 72; Comisión/Polonia (C-192/18), cit., ap. 109; Banco de Santan$\operatorname{der}$ S.A., cit., ap. 57 y ss.

49 SSTJ: Minister for Justice, cit., ap. 64; Comisión/Polonia (C-619/18), cit., ap. 75 y 76; Comisión/Polonia (C-192/18), cit., ap. 112 y 113; Banco de Santander S.A., cit., ap. 58 y ss.

50 SSTJ: Minister for Justice, cit., ap. 63 énfasis añadido; Comisión/Polonia (C-619/18), cit., ap. 73; Comisión/ Polonia (C-192/18), cit., ap. 110; Banco de Santander S.A., cit., ap. 61 (recordando su previa STJ Panicello, cit., ap. 38).

51 SSTJ: Minister for Justice, cit., ap. 66; Comisión/Polonia (C-619/18), cit., ap. 74; Comisión/Polonia (C-192/18), cit., ap. 111; A.K. y otros, cit., ap. 123; Banco de Santander S.A., cit., ap. 63; o en el Auto Comisión/ Polonia (C-791/19 R), cit., ap. 65. 
respecto a la inamovilidad ${ }^{52}$, el régimen salarial ${ }^{53}$ o a las garantías relativas al régimen disciplinario a aplicar, en su caso, a quien tiene esa misión de juzgar ${ }^{54}$. Como podremos observar en el apartado siguiente, se trata de unas reglas que, concretadas según estándares marcados por el Derecho de la Unión, y en última instancia por el TJ, son de obligado respeto y cumplimiento por parte de los Estados miembros.

De entre las diversas conclusiones que cabe deducir de cuanto se ha dicho, hay una que merece la pena destacar ahora, por lo que a estas páginas se refiere, y es la referida a la dimensión «estructural» que alcanza la «independencia judicial» en la última jurisprudencia del TJ que venimos señalando. Como señala de forma muy clarividente la profesora Paz Andrés, si bien, «tradicionalmente, el TJEU se ha venido ocupando de la independencia del poder judicial a propósito del concepto de órgano jurisdiccional nacional en relación con el art. 267 TFEU y la competencia para plantear cuestiones prejudiciales [...], en su jurisprudencia reciente el Tribunal ha superado esa visión específica vinculada a los elementos de la noción comunitaria de órgano jurisdiccional nacional y caracterizada por una cierta flexibilidad orientada a favorecer el diálogo judicial, para dar el salto a una dimensión constitucional en la que mediante una interpretación creativa del segundo apartado del artículo 19.1 TUE estima que el principio de la independencia judicial es inherente a esta disposición» ${ }^{55}$. En esta misma línea, P. Zinonos, afirmará que «debido

52 Por ejemplo, SSTJ: Comisión/Polonia (C-619/18), cit., ap. 76; Comisión/Polonia (C-192/18), cit., ap. 113.

53 Cfr. SSTJ ASJP, cit., ap. 45 y ss.; Escribano Vindel, cit., ap. 66 y ss.

54 SSTJ: Minister for Justice, cit., ap. 67; Comisión/Polonia (C-619/18), cit., ap. 77; Comisión/Polonia (C-192/18), cit., ap. 114; A.K. y otros, cit., ap. 123; ATJ Comisión/Polonia (C-791/19 R), cit., ap. 34 y 35.

55 P. Andrés SÁenz De Santa María, «Rule of Law and judicial Independence in the light of CJEU and ECtHR Case Law», en C. Izquierdo Sans, C. Martínez Capdevila y M. Nogueira Guastavino (eds.), Fundamental Rights Challenges - Horizontal Effectiveness, Rule of Law and Margin of National Appreciation, Springer, 2020 (en ed.), ap. 1. No es de extrañar, en este sentido, que el TJ haya endurecido el requisito de independencia a la hora de identificar qué es o no, según el Derecho de la Unión, un «órgano jurisdiccional» a los efectos de plantear la remisión prejudicial del artículo 267 TFUE. Así ha ocurrido en el as. Banco de Santander S.A. (cit.), donde, invocando las aquí mencionadas SSTJ ASJP y Comisión/Polonia (C-619/18), el Tribunal negó la condición de órgano jurisdiccional a efectos de plantear la prejudicial al Tribunal Económico Administrativo Central español, en un claro overruling respecto a la jurisprudencia previa al respecto (as. Gabalfrisa y otros, de 21 de marzo de 2000). Al respecto, pronosticando el cambio: M.J. GARCía VALDECASAS, «El Tribunal de Justicia, centinela...», op. cit., p. 86; véase, asimismo, Paz ANDrÉs SÁEnz De SANTA María, quien llama la atención sobre el hecho de que, si bien ello resulta explicable desde la dimensión del Estado de Derecho, no lo es tanto desde la perspectiva de la cuestión prejudicial, ya que excluye del diálogo con el TJ a diversos órganos que hasta el presente tenían abierta esa posibilidad (ibidem., ap. 1.2.3 in fine); P. ConCELlón, FERNÁNDEZ, «El concepto de órgano jurisdiccional nacional: una noción en permanente revisión», RDCE, 66, 2020, pp. 629 y ss.

Por lo demás, sobre la reciente jurisprudencia del TJ acerca de la noción de autoridad judicial respecto a los miembros del ministerio fiscal (en relación con la garantía de independencia en la emisión de órdenes de detención europea), véanse: la STJ OG (Fiscalía de Lübeck) y PI (Fiscalía de Zwickau), de 27 de mayo de 2019 (en la que el TJ considera que ambas fiscalías alemanas no ofrecen garantías de independencia frente al poder ejecutivo suficientes para poder emitir órdenes europeas de detención); la Sentencia $P F$, también de 27 de mayo de 2019 (en la que el TJ considerará que el concepto de autoridad judicial sí comprende al Fiscal General de un Estado miembro, como el de Lituania, que, siendo estructuralmente independiente del poder 
a su vínculo indivisible con el principio de protección judicial efectiva», la independencia judicial «manifiesta una obligación estructural de los Estados miembros en virtud del artículo 19, párrafo 1, párrafo 2, TUE y se convierte en un componente de la plena efectividad del Derecho de la Unión» ${ }^{56}$.

\section{LA DIMENSIÓN OBJETIVA DEL DERECHO FUNDAMENTAL A LA TUTELA JUDICIAL EFECTIVA COMO PARÁMETRO DE CONTROL DE EUROPEIDAD DE LAS MEDIDAS NACIONALES RELATIVAS A LA ADMINISTRACIÓN JUDICIAL}

La principal idea que se quiere señalar en este apartado consiste en destacar que la dimensión objetiva del derecho fundamental a la tutela judicial efectiva, una dimensión particularmente ligada a los arts. 2 (valor Estado de Derecho) y 19.1 (2) TUE, y concretada en la exigencia de garantizar la independencia judicial, está siendo empleada como parámetro de control de europeidad frente a las actuaciones de los Estados miembros que se oponen a la misma. En concreto, normalmente, ante medidas nacionales relativas a la organización y funcionamiento del Poder Judicial que la vulnerarían. Así lo ha hecho el Tribunal de Justicia en diversas resoluciones, y también otros sujetos como los órganos jurisdiccionales nacionales (planteando remisiones prejudiciales que, a la postre, van en este sentido) o la Comisión Europea (interponiendo recursos por incumplimiento al respecto).

En lo que sigue destacaremos tres cuestiones relacionadas con esta idea de utilizar el estándar europeo común sobre la tutela judicial efectiva como medida de control: en primer lugar, el ámbito de actuación nacional en el que rige ese estándar europeo; posteriormente, describiremos de forma sucienta los principales asuntos en los que se ha producido o activado el control, identificando el parámetro utilizado y la medida nacional controlada; y finalmente, apuntaremos telegráficamente varias ideas acerca de los mecanismos de control que se están utilizando para llevar a cabo ese control de europeidad en defensa de la dimensión objetiva de la tutela judicial efectiva en la Unión Europea.

\section{El radio de acción de la tutela judicial efectiva reconocida por el Derecho} de la Unión

¿Cuándo entra en juego la tutela judicial efectiva reconocida por el Derecho de la Unión? ¿Cuándo están los Estados miembros y sus órganos jurisdiccionales

judicial, es competente para ejercer la acción penal y goza en ese Estado miembro de un estatuto que le confiere una garantía de independencia frente al poder ejecutivo en el marco de la emisión de la orden de detención europea); de forma similar, la STJ JR e YC, de 12 de diciembre de 2019.

56 P. Zinonos, «Judicial Independence \& National Judges...», op. cit., p. 623. 
vinculados y regidos por su contenido? El TJ ha respondido a esta cuestión señalando que, en cuanto a su ámbito de aplicación, el segundo párrafo del art. 19.1 TUE «se refiere a los «ámbitos cubiertos por el Derecho de la Unión», con independencia de la situación en la que los Estados miembros apliquen este Derecho, en el sentido del artículo 51, apartado 1, de la Carta de los Derechos Fundamentales de la Unión Europea» ${ }^{57}$. Da la impresión de que, según entiende el TJ, los «ámbitos cubiertos por el Derecho de la Unión» [art. 19.1(2) TUE] son más extensos o de mayor alcance que aquellos en los que se «aplica» el mismo. Recuérdese que, de acuerdo con el art. 51 de la Carta DFUE, el ámbito interno de incidencia del derecho a la tutela judicial reconocido en el art. 47 de la misma «sólo» alcanza hasta donde se aplique el Derecho de la Unión ${ }^{58}$.

Por otro lado, resulta evidente que la dimensión objetiva o estructural de la tutela judicial efectiva - como núcleo del valor Estado de Derecho y con la garantía de la independencia judicial como exigencia primordial - es más acusada en el art. 19 TUE que en el 47 CDFUE $^{59}$. También parece claro que esta jurisprudencia

57 SSTJ: ASJP, cit., ap. 29; Comisión/Polonia (C-619/18), cit., ap. 50; Comisión/Polonia (C-192/18), cit., ap. 101; A.K. y otros, cit., ap. 82, o Miasto Łowicz, cit., ap. 33 [M.J. GARCía-VALDECASAS Dorrego señala en este sentido que con esa afirmación — hecha por primera vez en la STJ ASJP — «el Tribunal viene a distinguir entre ámbito de aplicación del artículo 19 TUE, ap. 1, párrafo 2 y el ámbito de aplicación del artículo 47 de la Carta, dado que mientras este último vendría delimitado por el artículo 51, apartado 1 CDFUE, el artículo 19 TUE tendría un ámbito propio que no dependería de si los Estados aplican o no aplican el Derecho de la Unión». La distinción entre los ámbitos de aplicación de cada uno de estos dos artículos «constituye así una de las aportaciones más importantes de la sentencia» («El Tribunal de Justicia, centinela...», op. cit., ap. III.2)].

Unido a lo anterior, el Tribunal afirmará también que esa disposición del art. 19 «es aplicable a cualquier instancia nacional que pueda pronunciarse, como órgano jurisdiccional, sobre cuestiones relativas a la aplicación o a la interpretación del Derecho de la Unión y que, por lo tanto, están comprendidas en los ámbitos cubiertos por este Derecho» (SSTJ: ASJP, cit., ap. 40; A.K. y otros, cit., ap. 83, o Miasto Eowicz, cit., ap. 34).

58 Reconociendo un ámbito de aplicación más amplio al art. 19.1(2) TUE que al art. 47 CDFUE: M. Bonelli y M. M. Claes, «Judicial serendipity: How Portuguese judges came to the rescue of the Polish judiciary», European Constitutional Law Review, 14, 2018, pp. 630 y ss.; L. PECH y S. Platon, «Judicial Independence under threat...», op. cit., pp. 7 y ss. y 13 y 14; K. LENAERTs, «On Judicial Independence and the Quest for National, Supranational and Transnational Justice», G. SELvik y otros (eds.), The Art of Judicial Reasoning. Festschrift in Honour of Carl Baudenbacher, Springer, 2019, p. 155; A. VON BogDANDY y L.D. SPIEKER, "Contra los jueces que silencian las críticas...», op. cit., ap. II.2; A. Torres, «From Portugal to Poland...», op. cit., pp. 112 y ss.; P. Van Elsuwege y F. Gremmelprez ( $P$ Protecting the Rule of Law in the EU Legal Order...», op. cit., pp. 25 y ss.), para quienes el Tribunal diseñó en la Sentencia ASJP un ámbito de aplicación más amplio del artículo 19.1 (2) TUE en el sentido de que el mismo se aplica a todos los campos cubiertos por la legislación de la UE, independientemente de si los Estados miembros están implementando Derecho de la UE en el sentido del Artículo 51 (1) CDFUE, y que debe ser cumplido por todos los jueces y tribunales que pueden ser llamados a pronunciarse sobre cuestiones relacionadas con la aplicación o interpretación del Derecho de la UE. El art. 47 de la Carta se utiliza como herramienta para la interpretación del Artículo 19.1 (2) TUE, proporcionando información útil sobre la implementación concreta del principio de protección judicial efectiva, con el principio de independencia del poder judicial como componente crucial.

59 Ayuda también a esta comprensión el dato de que mientras en esta disposición el sujeto de la oración y de la acción son «los Estados miembros» [establecerán las vías de recurso necesarias para garantizar la tutela judicial efectiva (...)], en el art. 47 ese sujeto hace referencia a la dimensión subjetiva, en concreto a «toda persona» [cuyos derechos y libertades garantizados por el Derecho de la Unión hayan sido violados tiene derecho a la tutela judicial efectiva (...)].Unido a ello, es interesante observar que, mientras la versión española de los mencionados arts. 19 TUE y 47 CDFUE utiliza en ambos casos, sin realizar distinciones, la expresión «tutela 
que venimos mencionando se fundamenta más en aquella disposición que en ésta (salvo en la STJ A.K. y otros), si bien es cierto que tiende a utilizar las dos (incluso en la STJ ASJP, en la que apenas se menciona el art. 47). Como destaca la profesora Paz Andrés, el TJ ha optado, al menos por el momento, por utilizar el segundo párrafo del art. 19.1 TUE en combinación con el art. 47 de la CDFUE a la hora de proteger la independencia judicial como elemento del Estado de Derecho ${ }^{60}$. En cualquier caso, el hecho es que, como veremos a continuación, el TJ está echando mano de estos artículos como muro de contención de las disposiciones nacionales relativas a la organización judicial que sean opuestas a esa tutela judicial efectiva reconocida en el Derecho de la Unión.

Como bien destaca el Tribunal, y lo hace en la mayoría de la jurisprudencia sobre el tema, «es preciso recordar que, si bien corresponde a los Estados miembros determinar cómo organizan su Administración de Justicia, no es menos cierto que, al ejercer esta competencia, deben cumplir las obligaciones que les impone el Derecho de la Unión y, en particular, el artículo 19 TUE, apartado 1, párrafo segundo ${ }^{61}$. Si no se cumple con ellas o una medida nacional las contradice, entonces ésta debe ser controlada, debiendo primar el Derecho de la Unión Europea.

judicial efectiva», la versión inglesa se refiere a dicha tutela distinguiendo entre dos expresiones: «effective legal protection» en el caso de aquel artículo del Tratado y «right to an effective remedy» en el caso del artículo de la Carta (énfasis añadido).

60 P. Andrés Sáenz De Santa María, «Rule of Law and Judicial Independence...», op. cit., punto 1.2 in fine. La prof. ${ }^{a}$ hace constar que, si bien el Abogado General, sin perjuicio de reconocer la naturaleza conexa de ambas disposiciones [en atención a que comparten sus fuentes legales, se inscriben en la matriz más amplia de los principios generales del Derecho de la Unión, existiendo una «pasarela constitucional» entre ambas disposiciones (Conclusiones al as. A.K. y otros, de 27 de junio de 2019, EU:C:2019:551, ap. 85)], había ya sugerido previamente una distinción entre las mismas [en el sentido de que una presunta vulneración de la independencia y la imparcialidad en el contexto de una deficiencia estructural es susceptible de abordarse sobre la base del artículo 19 TUE, apartado 1, mientras que el art. 47 de la CDFUE está más relacionado con el contexto en que un Estado miembro está aplicando el Derecho de la Unión en el sentido del artículo 51, apartado 1, de la Carta (Conclusiones al asunto Comisión/Polonia, C-192/18, EU:C:2019:529, ap. 101, énfasis añadido)], el TJ resolverá este asunto A.K. y otros, basando su decisión en el art. 47, pero sin hacer un examen separado de ambas disposiciones, sino desde la conexión entre ambas. Señalará en concreto que «el principio de tutela judicial efectiva de los derechos que el ordenamiento jurídico de la Unión confiere a los justiciables, al que se refiere el artículo 19 TUE, apartado 1, párrafo segundo, constituye un principio general del Derecho de la Unión que en la actualidad se reconoce en el artículo 47 de la Carta, de modo que el primero de estos preceptos obliga a todos los Estados miembros a establecer las vías de recurso necesarias para garantizar, en los ámbitos cubiertos por el Derecho de la Unión, la tutela judicial efectiva, especialmente en el sentido del segundo de estos preceptos» (cit., ap. 168).

61 SSTJ: Comisión/Polonia (C-619/18), cit., ap. 52 (apartado en el que también se añade que, «al exigir a los Estados miembros que cumplan estas obligaciones, la Unión no pretende en modo alguno ejercer por sí misma dicha competencia ni, por tanto, contrariamente a lo que alega la República de Polonia, que se la esté arrogando»); Comisión/Polonia (C-192/18), cit., ap. 102; Miasto Eowicz, cit., ap. 36; o ATJ Comisión/Polonia (C-791/19 R), cit., ap. 29.

A. Von BogdANDY y L.D. SPIEKER, recordarán que la función del art. 19.1.2 TUE es la de garantizar que el sistema judicial multinivel de la UE, un sistema judicial descentralizado reforzado basado en la cooperación entre el TJUE y los órganos jurisdiccionales nacionales, «funcione y que no surjan lagunas en la tutela judicial dentro del espacio jurídico de la UE. Esto implica la existencia de normas supranacionales relativas al poder judicial nacional, sus recursos y procedimientos» («Contra los jueces que silencian las críticas...», op. cit., II.2) 
Las medidas nacionales sobre la organización de la Administración de Justicia no son medidas de aplicación del Derecho de la Unión, pues responden a una competencia retenida por los Estados, pero entran en el ámbito cubierto por el Derecho de la Unión en cuanto afecten al (in)cumplimiento estatal del Derecho de la Unión. Lo mismo sucede en otros ámbitos de competencia estatal no atribuida a la Unión, como pueden ser, por ejemplo, la fiscalidad directa, la extradición de nacionales de Estados miembros a países terceros o las competencias sobre procedimiento penal no transferidas ${ }^{62}$.

\section{Los casos de control. Origen y desarrollo de una saga jurisprudencial}

Desde la STJ ASJP el TJ está utilizando la dimensión objetiva o estructural de la tutela judicial efectiva, esto es, la tutela judicial efectiva entendida como núcleo del valor Estado de Derecho, que comprende la independencia judicial como exigencia primordial, a modo de «un requisito sistémico que podría ser utilizado en abstracto para desafiar las medidas nacionales que afectan a la independencia de los jueces» nacionales ${ }^{63}$, a modo de un «parámetro relevante de revisión» al efecto ${ }^{64}$. Y así puede constatarse también en la progenie jurisprudencial de la Sentencia ASJP que venimos mencionando. Veámoslo brevemente.

62 El TJ se remite a este respecto a dos ejemplos interesantes (en el propio apartado 52 de la recién citada STJ Comisión/Polonia, C-619/18): Así, recordará que, si bien, a falta de normas de Derecho de la Unión que rijan la extradición de los nacionales de los Estados miembros a Rusia, los Estados miembros mantienen la competencia para adoptar tales normas, están también obligados a ejercerla con observancia del Derecho de la Unión, en particular de la prohibición de discriminación recogida en el artículo 18 TFUE, así como de la libertad de circulación y de residencia en el territorio de los Estados miembros, garantizada en el artículo 21.1 TFUE (STJ Raugevicius, de 13 de noviembre de 2018). Alude también a que, aun cuando los Tratados únicamente han atribuido competencias restringidas a la Unión en materia penal, se desprende sin embargo de la jurisprudencia del TJ que el Derecho de la Unión impone límites a la a la competencia estatal sobre la misma, pues ésta deberá ejercerse respetando las libertades fundamentales garantizadas por el Derecho de la Unión y todo el Derecho de la Unión en su conjunto. De manera que, «las normas de procedimiento penal nacional no pueden ser un obstáculo a la competencia que el artículo 14.2, párrafo segundo, de los Estatutos del SEBC y del BCE atribuye al Tribunal de Justicia en todos los casos en que sea aplicable esta disposición» (Rimšévičs y Bce/Letonia, de 26 de febrero de 2019, ap. 57).

63 L. Pech y S. Platon, «Judicial Independence under threat...», op. cit., p. 9 (énfasis en el original); véanse, asimismo, pp. 10 y ss.

64 D. Sarmiento, «On Constitutional Mode», Blog: Despite our Differences, de 6 de marzo de 2018, donde afirma que «de todos los principios consagrados en el artículo 19 del TUE, el Tribunal se centró en la independencia, que, según el Tribunal, no es un principio sólo relevante para los tribunales de la Unión, sino también para los tribunales nacionales. El artículo 19 TUE se ha transformado así en una norma crucial para el poder judicial de la Unión, entendido en un sentido federal, como un poder judicial de la federación y sus Estados. Y el garante del poder judicial, el garante último, es el Tribunal de Justicia. Todo un avance». Véanse también, sobre el tema: P. Andrés Sáenz De SANTa María, «Rule of Law and Judicial Independence...», op. cit., punto 1.2.1; M.J. García-Valdecasas Dorrego, «El Tribunal de Justicia, centinela de la independencia judicial...», op. cit., particularmente el ap. IV. R. Bustos GisBerT constata que el Tribunal «eleva la independencia judicial a principio con efecto directo accionable por parte de cualquier ciudadano o tribunal», en: «Sobre la independencia judicial (Notas al hilo del libro de Pablo Lucas Murillo de la Cueva, La independencia judicial y el gobierno de los jueces. Un debate constitucional)», TRC, 44, 2019, p. 385. 
a) En la mencionada Sentencia Associação Sindical dos Juízes Portugueses $(A S J P)$, de 27 de junio de 2018, se analizará, a la postre, si una medida nacional (en este caso, una ley portuguesa), que incidía en el régimen retributivo del juez nacional rebajándolo, afectaba con ello a la independencia judicial reconocida en el Derecho de la Unión ${ }^{65}$. El Tribunal llegará a la conclusión de que el principio de independencia judicial de la Unión no se opone a que se apliquen a los miembros del Tribunal nacional medidas generales de reducción salarial puesto que — vinculadas a exigencias imperativas de supresión del déficit presupuestario excesivo y a un programa de ayuda financiera de la Unión- se aplicaban a todos los miembros de la administración pública nacional, no sólo a los jueces, y tenían sólo una dimensión temporal. Pero el hecho es que, en cualquier caso, con esta resolución se inaugura, de alguna manera, un control de comunitariedad/europeidad atinente al respeto de la independencia judicial, entendida como exigencia de la protección judicial efectiva del Derecho de la Unión conexa al valor Estado de Derecho. Ocho meses más tarde, el Tribunal volverá a controlar y resolver en el mismo sentido otro asunto (as. Escribano Vilndel) de contraste entre la independencia judicial reconocida en la Unión y una medida nacional de reducción salarial ${ }^{66}$.

65 El asunto, descrito de forma sumaria, trae causa de una cuestión prejudicial planteada por el Tribunal Supremo Administrativo portugués, que tiene por objeto la interpretación de los art. 19.1(2) TUE y 47 CDFUE. Se trata de una remisión prejudicial que se plantea en el marco de un litigio entre la mencionada Asociación, que actúa en representación de los miembros del Tribunal de Cuentas, en relación con la reducción salarial — de carácter temporal—a los miembros de dicho órgano de acuerdo con las líneas directrices de la política presupuestaria del Estado portugués destinadas a reducir su déficit presupuestario excesivo. La Ley n. ${ }^{\circ} 75 / 2014$ redujo las retribuciones de una serie de cargos públicos y personas que ejercían funciones en el sector público, y la ASJP recurrió ante el Tribunal Supremo los actos de aplicación de la misma a los miembros del Tribunal de Cuentas, aludiendo que ello implicaba la violación de la Constitución portuguesa y de los mencionados arts. del Derecho de la Unión, lo cual terminó concretándose en el planteamiento de la prejudicial. Sobre la Sentencia, entre otros muchos: L. PECH y S. PLATON, «Judicial Independence under threat: the Court of Justice to the rescue», Common Market Law Review, 55, 6, 2018, pp. 1827 y ss.; M. Bonelli y M. Claes, «Judicial serendipity: How Portuguese judges...», op. cit., pp. 622 y ss.); M.J. Garciá-ValdeCASAS Dorrego, El Tribunal de Justicia, centinela de la independencia judicial...», op. cit.; P. ANDrÉs SÁENZ De SAnta María, «Rule of Law and judicial Independence ...», op. cit., ap. 1.2.1; A. Torres Pérez, «From Portugal to Poland...», op. cit., pp. 105 y ss.; M. CAMPos SÁNCHEZ-BordonA, «La protección de la independencia judicial...», op. cit., pp. 11 y ss.; P. ZinONOs, «Judicial Independence \& National Judges...», op. cit., pp. 615 y ss.

66 STJ de 7 de febrero de 2019, cit. supra. Una petición prejudicial planteada por el TSJ de Cataluña, en el marco de un litigio en el que se impugnaba una disminución retributiva generada por medio de unos actos administrativos adoptados sobre la base del art. 31 de la LGPE 2011. El Tribunal remitente se preguntaba, entre otras cuestiones, si la actuación nacional generaba una discriminación por razón de la edad prohibida por la Carta (art. 21) y por la Directiva 2000/78 (relativa al establecimiento de un marco general para la igualdad de trato en el empleo y la ocupación), y si era contraria a la independencia judicial (todo ello, sin perjuicio de que, previamente, el Tribunal había planteado una cuestión de inconstitucionalidad que fue inadmitida por el TC español, en atención a que la disposición controvertida no vulneraba, en particular, el principio de igualdad consagrado en el artículo $14 \mathrm{CE}$ ). 
b) La siguiente sentencia clave de esta saga jurisprudencial es la recaída en el asunto Minister for Justice and Equality, de 25 de julio de 2018, ya citada, que deriva de una cuestión planteada por la High Court (Tribunal Superior) de Irlanda, en relación con la ejecución de tres órdenes de detención europeas emitidas por un tribunal polaco a efectos de su enjuiciamiento penal. La cuestión prejudicial se enmarca en el contexto de las recientes y sucesivas reformas legislativas del sistema judicial realizadas en la República de Polonia desde $2015^{67}$, por cuyo efecto combinado se habría vulnerado, a juicio del tribunal remitente, el Estado de Derecho en dicho país ${ }^{68}$ (medidas que llevaron a la Comisión Europea a presentar en 2017 una propuesta motivada en la que instaba al Consejo a declarar, de conformidad con el artículo 7.1 TUE, la existencia de un riesgo claro de violación grave del Estado de Derecho por parte de Polonia).

Sobre esta base el tribunal a quo preguntaba al TJ si la autoridad judicial de ejecución de la euroorden que puede dar lugar a una violación del derecho fundamental de la persona buscada a un proceso equitativo, está obligada, de conformidad con la sentencia Aranyosi y Căldăraru ${ }^{69}$, por un lado, a asegurarse de que existe un riesgo real de que se viole ese derecho fundamental debido a deficiencias sistémicas del sistema judicial polaco $\mathrm{y}$, por otro lado, a comprobar que la persona de que se trata está expuesta a ese riesgo de ser entregada a dicho país.

La respuesta del Tribunal de Justicia parte de la idea de que la salvaguarda de la independencia de la autoridad judicial resulta primordial para garantizar la tutela judicial efectiva de los justiciables. Sobre esta base, y siguiendo la mencionada sentencia, entiende que en el supuesto de que la persona que es objeto de una orden de detención europea invoque, para oponerse a su entrega a la autoridad judicial emisora, la existencia de deficiencias sistémicas o generalizadas, que puedan afectar a la independencia del poder judicial del Estado miembro emisor y a su derecho fundamental a un proceso equitativo garantizado en el art. 47 CDFUE (y la información recopilada por la Comisión Europea en la propuesta motivada que presentó al Consejo de conformidad con el artículo 7.1 TUE sería pertinente a tales efectos), la autoridad judicial de ejecución deberá evaluar, además, basándose en elementos objetivos, fiables, precisos y debidamente actualizados, si existe un riesgo real de que se le viole a la persona ese derecho en el Estado miembro emisor, como

67 Medias relativas, en particular, al Trybunat Konstytucyjny (Tribunal Constitucional), al Sąd Najwyższy (Tribunal Supremo), al Consejo Nacional del Poder Judicial, a la organización de los órganos jurisdiccionales ordinarios, a la Escuela Nacional de la Judicatura y al Ministerio Fiscal.

68 Sobre el asunto, por ejemplo: M. CAMPOS SÁNCHEZ-BordONA, «La protección de la independencia judicial...», op. cit., pp. 14 y ss.; P. ZINONOS, «Judicial Independence \& National Judges...», op. cit., pp. 618 y ss.

69 STJ de 5 de abril de 2016. 
consecuencia de la falta de independencia de los órganos jurisdiccionales de dicho Estado miembro, debido a las referidas deficiencias ${ }^{70}$.

La presunción de que los demás Estados respetan los derechos fundamentales — derivada del reconocimiento y la confianza mutuos entre Estados miembros - sólo se puede romper en circunstancias muy excepcionales, bajo ese doble control señalado en la mencionada STJ Aranyosi y Căldăraru a propósito de las violaciones de los derechos fundamentales en el Estado miembro emisor de las órdenes europeas de detención y entrega. En aquel caso el control se propugnó con relación a si la entrega podía implicar la violación de que la persona sea sometida a un trato inhumano o degradante prohibido en el art. 4 CDFUE; y en este asunto lo es con referencia al riesgo de vulnerar el derecho fundamental a un juez independiente y, con ello, del contenido esencial del derecho fundamental a un proceso equitativo, garantizado por el artículo 47 de la misma ${ }^{71}$.

Por lo que ocupa a estas páginas, una de las cosas más interesantes de la sentencia consiste en que, como ha destacado María José García-Valdecasas, la misma «pone en valor el control que también corresponde realizar a los Estados en lo que concierne al respeto de la tutela judicial efectiva como parte del Estado de Derecho», teniendo en cuanta que «esta vez no es el Tribunal de Justicia el que controla, sino que son los órganos jurisdiccionales de los Estados miembros los que se controlan de forma horizontal» ${ }^{72}$.

c) La tercera de las sentencias cruciales en esta materia es la derivada de un recurso por incumplimiento interpuesto por la Comisión Europea contra la República de Polonia: la STJ Comisión/Polonia, de 24 de junio de 2019 (C-619/18), sobre la independencia del Tribunal Supremo, recaída, como puede verse, justo al año de pronunciarse la STJ ASJP. En este caso, las medidas nacionales que suscitan el control son determinadas disposiciones de la nueva Ley del Tribunal Supremo (y de posteriores leyes modificativas de la misma) que entró en vigor el 3 de abril de 2018. La demanda de la Comisión solicita al Tribunal de Justicia que declare que la República de Polonia ha incumplido, mediante esas disposiciones, las obligaciones que le incumben en virtud del artículo 19 TUE, apartado 1, párrafo segundo, en relación con el artículo 47 de la CDFUE. Tal incumplimiento se genera,

70 STJ Minister for Justice, cit., ap. 60-61.

71 STJ Minister for Justice, cit., ap. 59. Como ha señalado el Abogado General M. CAMPos SÁNCHEZ-BORDONA, la importancia de esta sentencia radica, probablemente, «en su iter argumentativo sobre la independencia judicial. Ese factor ejerce un destacado papel en el mecanismo de la orden de detención europea, modalidad de cooperación penal entre autoridades judiciales que tiene como presupuestos los principios de confianza recíproca y reconocimiento mutuo entre los Estados miembros. Principios que, a su vez, solo pueden desplegar su virtualidad si las autoridades judiciales, de emisión y de recepción, tienen en común la nota de independencia» («La protección de la independencia judicial...», op. cit., p. 16).

72 «El Tribunal de Justicia, centinela...», op. cit., ap. IV. 
«por una parte, al reducir la edad de jubilación de los jueces del Sąd Najwyższy (Tribunal Supremo, Polonia) y aplicar esta medida a los jueces de dicho Tribunal en ejercicio nombrados antes del 3 de abril de 2018 y, por otra parte, al atribuir al presidente de la República la facultad discrecional para prorrogar la función jurisdiccional en activo de los jueces de ese Tribunal una vez alcanzada la nueva edad de jubilación ${ }^{73}$.

La Comisión formuló también, al mismo tiempo y mediante escrito separado, una demanda de medidas provisionales (ex. art. 279 TFUE y 160.2 del Reglamento de Procedimiento del Tribunal de Justicia) solicitando que, a la espera de la sentencia que dirimiera la cuestión de fondo, se suspendiera la aplicación de las mencionadas disposiciones, y se adoptaran todas las medidas necesarias para que los jueces pudiesen continuar ejerciendo sus funciones en los mismos puestos, sin que se pudieran adoptar medidas para sustituirlos. Mediante Auto de 19 de octubre de $2018^{74}$, solo dos semanas más tarde, la vicepresidenta del Tribunal estimó provisionalmente la demanda de medidas provisionales hasta la adopción del auto que pusiera fin al procedimiento cautelar, segundo auto que fue adoptado, por la Gran Sala, el 17 de diciembre de 2018, acogiendo las medidas cautelares solicitadas por la Comisión ${ }^{75}$.

Constatado que el Tribunal Supremo es un órgano jurisdiccional nacional que [en la medida que puede verse abocado a resolver sobre cuestiones vinculadas a la aplicación o la interpretación del Derecho de la Unión, y que forma parte del sistema polaco de vías de recurso «en los ámbitos cubiertos por el Derecho de la Unión» en el sentido del artículo 19.1 (2) TUE] queda sujeto a las exigencias de la tutela judicial efectiva ${ }^{76}$, entre las que se encuentra el respeto por la independencia judicial, el TJ entra a analizar si las disposiciones nacionales controvertidas son o no contrarias a la misma. Concluirá en este sentido que la medida de reducción de la edad de jubilación de los jueces del Tribunal Supremo que están en activo, entraña «un cese anticipado del ejercicio de la función jurisdiccional» de los mismos, «y que, por ello, puede suscitar inquietudes legítimas en cuanto al respeto del principio de inamovilidad del juez ${ }^{77}$. Por otro lado, entiende, asimismo, que la medida de atribuir al presidente de

73 Véanse ap. 1, 25 y 26 de la Sentencia.

74 Auto TJ Comisión/Polonia, C-619/18 R (no publicado).

75 Auto TJ Comisión/Polonia, C-619/18 R, EU:C:2018:1021.

76 Ap. 56 de la STJ Comisión/Polonia, C-619/18 (citando el previo ATJ de 17 de diciembre de 2018, Comisión/Polonia, cit., ap. 43).

77 STJ Comisión/Polonia, C-619/18, ap. 78. Una medida cuya aplicación sólo puede admitirse si está justificada por «un objetivo legítimo y es proporcionada en relación con este, y siempre que no permita suscitar dudas legítimas en el ánimo de los justiciables en lo que respecta a la impermeabilidad del tribunal de que se trate frente a elementos externos y en lo que respecta a su neutralidad con respecto a los intereses en litigio» (Ibid., ap. 79). 
la República la facultad discrecional para prorrogar la función jurisdiccional en activo de los jueces de ese Tribunal, una vez alcanzada la nueva edad de jubilación, puede también menoscabar la independencia judicial. Y ello «por cuanto su adopción no está en sí sometida a ningún criterio objetivo y verificable y no debe estar motivada. Además, no cabe interponer recurso judicial contra esa decisión ${ }^{78}$.

De las múltiples reflexiones que genera la Sentencia resulta particularmente interesante traer aquí a colación, por su conexión con nuestro tema, las dos que resalta el Abogado General en el TJ, Campos Sánchez-Bordona ${ }^{79}$ : por un lado, el énfasis que el Tribunal de Justicia pone en la percepción o en la impresión que reciben los justiciables sobre la independencia judicial, señalando la necesidad de que se excluya toda duda legítima en el ánimo de los mismos en lo que respecta a la impermeabilidad de los órganos jurisdiccionales frente a elementos externos y en lo que respecta a su neutralidad con respecto a los intereses en litigio ${ }^{80}$. Por otro lado, que la sentencia aborda también, desde la perspectiva de la independencia judicial, y con prudencia, la delicada cuestión del nombramiento de los jueces, incluida la intervención de órganos como los Consejos del Poder Judicial, llegando a formular tesis (como la que exige que el Consejo Nacional del Poder Judicial de aquella República «sea independiente de los Poderes Legislativo y Ejecutivo») ${ }^{81}$ que suscitarían reticencias en determinados Estados miembros.

d) A solo cuatro meses y medio de la anterior resolución, el TJ resolverá un nuevo recurso por incumplimiento: la Sentencia Comisión/Polonia (C-192/18), de 5 de noviembre de 2019, relativa, en este caso, a la independencia de los tribunales ordinarios. Otra resolución importante y significativa en este grupo de decisiones del TJ que muestran la existencia de un control de europeidad sobre medidas nacionales relativas a la Administración de justicia en atención al respeto de la tutela judicial efectiva y de la independencia judicial en los ámbitos cubiertos por el Derecho de la Unión.

En este caso, el control que activa la Comisión y resuelve el TJ lo será sobre la Ley por la que se modifican la Ley de Organización de los Tribunales Ordinarios y otras leyes, de 12 de julio de 2017, debido al incumplimiento

78 STJ Comisión/Polonia, C-619/18, ap. 114.

79 M. Campos Sánchez-Bordona, «La protección de la independencia judicial...», op. cit., pp. 20-21.

80 Cfr. STJ Comisión/Polonia, C-619/18, ap. 74

81 STJ Comisión/Polonia, C-619/18, ap. 116. El Tribunal volverá a referirse a la necesidad de que, «conforme al principio de separación de poderes que caracteriza el funcionamiento de un Estado de Derecho, deb[a] garantizarse la independencia de los tribunales frente a los Poderes Legislativo y Ejecutivo», tanto en la STJ A.K. y otros, cit., ap. 124 y 125, como en el ATJ 791/19 R, cit., ap. 66 a 68, en estos casos, en relación con el nombramiento de los miembros de la Sala Disciplinaria. 
de dos tipos de obligaciones. Por una parte, las que incumben a dicho Estado miembro en virtud del artículo 157 TFUE (principio de igualdad de retribución entre trabajadores y trabajadoras para un mismo trabajo o para un trabajo de igual valor) y la Directiva 2006/54/CE (relativa a la aplicación del principio de igualdad de oportunidades e igualdad de trato entre hombres y mujeres en asuntos de empleo y ocupación), al establecer esa Ley una edad de jubilación diferente para las mujeres y los hombres que desempeñan el cargo de juez en los tribunales ordinarios o el cargo de fiscal. Y por otra, por incumplir las que «le incumben en virtud del artículo 19 TUE, apartado 1, párrafo segundo», al facultar al ministro de Justicia, mediante la mencionada Ley, para autorizar o denegar la prórroga del ejercicio del cargo de los jueces de los tribunales ordinarios una vez alcanzada la nueva edad de jubilación de estos (que era reducida por la misma Ley).

El control de europeidad de las medidas nacionales discriminatorias no es un control novedoso, pero sí, en cambio, el de las disposiciones internas relativas a la organización judicial no respetuosas con la tutela judicial efectiva, el cual da con esta sentencia otro paso más para reafirmarse.

e) La sentencia A.K. y otros, de 19 de noviembre de 2019, es la siguiente resolución de la saga jurisprudencial que venimos describiendo, la quinta sentencia importante a menos de año y medio de aquella - ASJP — que dio origen a la misma, en este caso relativa a la independencia de la Sala Disciplinaria del Tribunal Supremo de la República de Polonia (se trata de la cuarta sentencia por lo que a la falta de independencia judicial de este país se refiere). La resolución responde a tres peticiones prejudicia$\operatorname{les}^{82}$, planteadas por la Sala de lo laboral del Tribunal Supremo polaco, surgidas en el marco de sendos litigios entre, por una parte, A.K., juez del Tribunal Supremo de lo Contencioso-Administrativo de Polonia, y el Consejo Nacional del Poder Judicial (CNPJ) de ese país; y, por otra parte, CP y DO, jueces del Tribunal Supremo polaco y este último tribunal. Unos litigios que surgen en relación con la jubilación forzosa anticipada de tales jueces y, más en concreto, con la independencia de la nueva Sala Disciplinaria del Tribunal Supremo aprobada por la reciente y ya mencionada nueva Ley del Tribunal Supremo, la cual reserva a esa Sala Disciplinaria la competencia exclusiva para conocer de los litigios relativos a la jubilación forzosa de los jueces del Tribunal Supremo ${ }^{83}$.

82 Que tienen por objeto la interpretación de los artículos 2 y 19.1 (2) TUE, del artículo 267 (3) TFUE, del artículo 47 CDFUE y del art. 9.1 de la Directiva 2000/78/CE del Consejo, de 27 de noviembre de 2000, relativa al establecimiento de un marco general para la igualdad de trato en el empleo y la ocupación (artículo referido a la tutela judicial efectiva en el ámbito de aplicación de la Directiva).

83 La reciente Ley por la que se modifican la Ley del Consejo Nacional del Poder Judicial y otras leyes, de 8 de diciembre de 2017, modificará, asimismo, el sistema de elección de los miembros del mencionado CNPJ (haciendo que quince de ellos sean nombrados por la Dieta, Cámara Baja del Parlamento polaco, y no 
El TJUE sentenciará que el derecho a la tutela judicial efectiva, garantizado por el artículo 47 CDFUE se opone a que unos litigios relativos a la aplicación del Derecho de la Unión puedan ser de la competencia exclusiva de un órgano que no constituye un tribunal independiente e imparcial. Señalará que «así ocurre cuando las condiciones objetivas en las que se creó el órgano de que se trate, sus características y la manera en que se ha nombrado a sus miembros puedan suscitar dudas legítimas en el ánimo de los justiciables en cuanto a la impermeabilidad de este órgano frente a elementos externos, en particular frente a influencias directas o indirectas de los poderes Legislativo y Ejecutivo, y en cuanto a su neutralidad con respecto a los intereses en litigio, y por lo tanto pueden dar lugar a una falta de apariencia de independencia o de imparcialidad de dicho órgano susceptible de menoscabar la confianza que la Administración de Justicia debe inspirar en los justiciables en una sociedad democrática» ${ }^{84}$. Dicho lo cual, el Tribunal aclarará que corresponde al órgano jurisdiccional remitente determinar, teniendo en cuenta todos los datos pertinentes de que disponga, si este es el caso de un órgano como la Sala Disciplinaria del Tribunal Supremo ${ }^{85}$. Y si el Tribunal remitente apreciara que tal es el caso, de ello resultaría que la mencionada Sala no cumpliría las exigencias de independencia e imparcialidad del artículo 47 de la Carta ${ }^{86}$, debiendo entonces concluir que «el principio de primacía del Derecho de la Unión obliga al órgano jurisdiccional remitente a dejar inaplicada la disposición del Derecho nacional» que reserva la competencia para conocer de los litigios principales a dicho órgano ${ }^{87}$.

por sus homólogos, como anteriormente), el cual juega un papel fundamental en la elección de los miembros de la Sala Disciplinaria.

84 El Tribunal de Justicia se apoyará en esta Sentencia en la jurisprudencia del TEDH relativa al art. 6 $\mathrm{CEDH}$, que exige que los tribunales sean independientes tanto de las partes como del ejecutivo y el legislativo (ap. 126 y ss. de la STJ). Cfr. Al respecto, por ejemplo, CAmpos SÁnCHEZ-BordonA, «La protección de la independencia judicial...», op. cit., p. 23. Sobre la jurisprudencia del TEDH en la materia, entre otros: P. Andrés SÁenz De SANTa María, «Rule of Law and judicial Independence ...», op. cit., ap. 2; J.M. Cortés MARTín, «Sorteando los inconvenientes del artículo 7 TUE..., op. cit., pp. 495 y ss.

85 Ap. 171 de la Sentencia; véase, también, el ap. 153.

86 Ap. 153 y 154 de la Sentencia.

87 Ibidem, ap. 155 y ss., especialmente ap. 171. Sobre la Sentencia, entre otros: P. ANDrÉs SÁEnz DE SANTA MARÍA, «Rule of Law and judicial Independence ...», op. cit., ap. 1.2.3; CAMPos SÁnCheZ-Bordona, «La protección de la independencia judicial...», op. cit., pp. 22 y ss. Es interesante señalar que, recibida la respuesta del Tribunal de Luxemburgo, el Tribunal remitente dictó sentencia el 5 de diciembre de 2019 (en el caso de apelación presentado por A. K. contra la resolución del CNPJ) en la que declara que, en su formación actual, el Consejo Nacional del Poder Judicial no es un órgano imparcial e independiente respecto de los poderes legislativo y ejecutivo, afirmando que la Sala Disciplinaria no es un órgano jurisdiccional en el sentido del Artículo 47 CDFUE, del art. 6 CEDH y del art. 45 (1) de la Constitución de la República de Polonia, y que, en consecuencia, su resolución debe ser anulada (Supreme Court of the Republic of Poland, Judgment of 5 December 2019, Case ref. III PO 7/18). Como se ha señalado muy significativamente al hilo de esta Sentencia, apelando precisamente a la dimensión objetiva o estructural de la independencia judicial y la tutela judicial: «la independencia de los tribunales y la imparcialidad de los jueces es para los ciudadanos igual que la 
f) La cuestión del régimen disciplinario del Tribunal Supremo va a dar juego, todavía, para otras resoluciones del TJ. En primer lugar, la Sentencia Miasto Łowicz (GS) de 26 de marzo de 2020, en relación con el régimen disciplinario aplicable a los jueces nacionales, que trae causa de las peticiones de decisión prejudicial remitidas por dos Tribunales Regionales de Polonia, en las cuales se planteaba, en esencia, al Tribunal de Justicia la cuestión de la conformidad de la nueva normativa polaca relativa al régimen de procedimiento disciplinario contra los jueces con el derecho de los justiciables a la tutela judicial efectiva, garantizada en el artículo 19.1 (2) TUE $^{88}$. El Tribunal de Justicia declaró la inadmisibilidad de las peticiones de decisión prejudicial remitidas, sobre la base de que no se daba la necesidad de la resolución prejudicial de interpretación al no existir un vínculo de conexión entre esa disposición cuya interpretación se solicita y los litigios principales.

Más allá de que el TJUE se haya podido mostrar (o no) más renuente o recatado que en sentencias anteriores en la defensa de la tutela judicial

libertad de expresión para los periodistas. Las garantías estatutarias de un estado democrático regido por el estado de derecho no se preservarán sin garantizar la independencia real de los tribunales y la imparcialidad de los jueces. Un juez privado de este atributo no puede resolver correctamente los conflictos y servir para mantener la paz pública. Los juicios de dicho juez, incluso a pesar de su corrección objetiva, no serán aceptados por las partes en una disputa o por el público. Esto fue señalado por el Tribunal Constitucional en su sentencia de 1993 [ «Oral justification of the Supreme Court judgment in connection with the CJEU ruling regarding the Disciplinary Chamber and the National Council of the Judiciary» (Supreme Court judgment of 5 December 2019 in case in which it requested the Court of Justice for preliminary ruling of 19 November 2019), Blog: Rule of Law. Everytbing you need to know about the rule of law in Poland, https://ruleoflaw.pl, 8 December 2019]. En cualquier caso, hay que señalar, asimismo, que la República de Polonia reaccionó contra la STJ A.K. y otros, entre otras medidas, adoptando el 20 de diciembre de 2019, la Ley por la que se modifican la Ley de Organización de la Jurisdicción Ordinaria, la Ley relativa al Tribunal Supremo y otras leyes (también conocida como «muzzle law», la cual entró en vigor el 14 de febrero de 2020), «que tiene por objeto endurecer considerablemente el régimen disciplinario aplicable a los jueces y dispone, en particular, para privar de efecto a la citada sentencia del Tribunal de Justicia, que la validez del nombramiento de un juez o la legitimidad de un órgano constitucional no pueden ser impugnados por un tribunal, so pena de que se inicie un procedimiento disciplinario contra los jueces que lo integran. A estos mismos efectos, dicha Ley somete ahora cualquier examen de alegaciones relativas a la falta de independencia de un juez o de un órgano jurisdiccional a la competencia exclusiva de la Izba Kontroli Nadzwyczajnej i Spraw publicznych Sądu Nawyższego (Sala de Control Extraordinario y de Asuntos Públicos del Tribunal Supremo, Polonia), recientemente instituida y que presenta, especialmente en lo que respecta al proceso de nombramiento de sus miembros, vicios análogos a los que señaló el Tribunal de Justicia respecto de la Sala Disciplinaria del Tribunal Supremo en su sentencia de 19 de noviembre de 2019, A. K. y otros (Independencia de la Sala Disciplinaria del Tribunal Supremo)» (Indicado por el Defensor del Pueblo, según se describe en la STJ Miasto Łowicz, cit., ap. 25).

88 Las peticiones se presentaron, por una parte, en el contexto de un litigio entre ciudad de Łowicz y el Tesoro Público con relación a una solicitud de pago de fondos públicos, y, por otra parte, en el contexto de un procedimiento penal incoado contra determinadas personas por haber participado en secuestros con fines lucrativos. Ambas peticiones indicaban el temor de que, si los casos se resolvían en determinada dirección, pudiera incoarse un procedimiento disciplinario contra el juez único encargado de cada asunto principal. Un temor surgido, en esencia, por el hecho de que, como consecuencia de las diversas reformas legislativas recientemente realizadas en Polonia, la objetividad e imparcialidad de los procedimientos disciplinarios contra los jueces ya no están garantizadas y la independencia de los órganos jurisdiccionales remitentes resulta afectada. 
efectiva y del Estado de Derecho a través del art. 19 TUE $^{89}$, lo cierto es que la resolución deja dos datos interesantes a efectos de nuestro tema. Por un lado, que los órganos jurisdiccionales continúan intentando vehicular un control de europeidad sobre normas relativas a la organización judicial (en este caso, en relación con las medidas polacas de 2017 que establecen el régimen disciplinario en cuestión) a través de la prejudicial, utilizando el mencionado artículo como parámetro normativo. Por otro lado, el Tribunal aprovechará la ocasión para recordar que «no cabe admitir que disposiciones nacionales expongan a los jueces nacionales a procedimientos disciplinarios por haber planteado una petición de decisión prejudicial al Tribunal de Justicia» ${ }^{90}$. Unido a ello, declarará, asimismo, que el hecho de que los jueces no estén expuestos a tales procedimientos o sanciones disciplinarios «constituye, además, una garantía inherente a su independencia (...), que es esencial para el buen funcionamiento del sistema de cooperación judicial ínsito en el mecanismo de remisión prejudicial previsto en el artículo 267 TFUE» $^{91}$.

En segundo lugar, se encuentra el Auto del TJ Comisión/Polonia (C-791/19 R), de 8 de abril de 2020, adoptado en Gran Sala, por el que, atendiendo la demanda de medidas provisionales formulada por la Comisión Europea el 23 de enero de 2020, el Tribunal ordena a Polonia suspender inmediatamente la aplicación de las disposiciones nacionales sobre los poderes de la Sala Disciplinaria del Tribunal Supremo con respecto a los casos disciplinarios relacionados con jueces. Puede volver a observarse cómo el Tribunal utiliza otra vez las medias provisionales del art. 279 TFUE a modo de mecanismo de control de europeidad de las medidas nacionales. La demanda y la resolución de medidas cautelares se ubican en el marco de otro recurso por incumplimiento contra Polonia, todavía pendiente de resolución, interpuesto por la Comisión, el 25 de octubre de 2019, en este caso, dicho de forma resumida, en atención a que el nuevo régimen disciplinario del que venimos hablando, establecido en Polonia a partir de las medidas de 2017, sería contrario al Derecho de la Unión, por incumplir las obligaciones que le incumben en virtud del art. 19.1 (2) TUE $^{92}$. Las señaladas pretensiones cautelares de la Comisión obedecieron

89 Al respecto, entre otros: y L.D. SPIEKER, «The Court gives with one hand and takes away with the other: The CJEU's judgment in Miasto Eowicz», VerfBlog, de 2020/3/26.

90 Ap. 59 de la Sentencia (habiendo destacado el papel crucial que juega la figura del art. 267 TFUE en la arquitectura jurisdiccional de la Unión, ap. 55 y ss.), citando al respecto el previo Auto del presidente del Tribunal de Justicia, de 1 de octubre de 2018, Miasto Eowicz, C-558/18 y C-563/18, no publicado, ap. 21. 91 Apartado 59 de la Sentencia, recordando, en el mismo sentido, la previa STJ Minister For Justice, cit., ap. 54.

92 Incumplimientos derivados de: permitir que el contenido de las resoluciones judiciales pueda ser calificado de infracción disciplinaria respecto a los jueces de los tribunales ordinarios (en la Ley de 
a que la mencionada Cámara disciplinaria seguía operando a pesar de lo apuntado sobre ella en la ya comentada STJ A.K. y otros, de noviembre del mismo año.

El Tribunal entendió que la aplicación de las disposiciones nacionales controvertidas, en la medida en que atribuyen la competencia para conocer de los procedimientos disciplinarios relativos a los jueces del Tribunal Supremo y de los tribunales ordinarios a un órgano, como la Sala Disciplinaria, cuya independencia podría no estar garantizada, «puede ocasionar un perjuicio grave e irreparable para el ordenamiento jurídico de la Unión» ${ }^{93}$.

Hay que señalar, por lo demás, que no estamos ante un fenómeno aislado, o reducido a la República de Polonia. A partir del desarrollo de la mencionada saga jurisprudencial han empezado a proliferar bastantes procedimientos prejudiciales en diversos Estados miembros, también en relación con la tutela judicial efectiva y la independencia judicial. El Abogado General M. Campos Sánchez-Bordona señala, en este sentido, que «el «descubrimiento» de la independencia como cualidad de los órganos judiciales que puede ser sometida a la consideración del Tribunal de Justicia está dando lugar a un incremento de las cuestiones prejudiciales que ponen en entredicho las normas nacionales reguladoras de sus instituciones jurisdiccionales» ${ }^{94}$.

Así, además de las que se han seguido remitiendo desde Polonia ${ }^{95}$, están las presentadas recientemente, en la misma línea, por tribunales de otros Estados como:

Organización de los Tribunales Ordinarios, y en la Ley del Tribunal Supremo); no garantizar la independencia y la imparcialidad de la Sala Disciplinaria (Ley del Tribunal Supremo, en relación con la modificada Ley del Consejo Nacional del Poder Judicial); atribuir al presidente de la Sala Disciplinaria la facultad discrecional para designar al tribunal disciplinario de primera instancia en los procedimientos relativos a los jueces de los tribunales ordinarios (Ley de Organización de los Tribunales Ordinarios) y, de ese modo, no garantizar que los procedimientos disciplinarios sean examinados por un tribunal «establecido por la ley»; o al atribuir al ministro de Justicia la facultad para nombrar a un responsable de la acción disciplinaria del ministro de Justicia (Ley de Organización de los Tribunales Ordinarios) y, de ese modo, no garantizar que los procedimientos disciplinarios seguidos contra los jueces de los tribunales ordinarios se resuelvan en un plazo razonable, y al establecer que las actuaciones relativas a la designación de un defensor y a la asunción de la defensa por este no tienen como efecto la suspensión del procedimiento disciplinario (Ley de Organización de los Tribunales Ordinarios) y que el tribunal disciplinario debe dar curso al procedimiento aun en caso de incomparecencia justificada del juez inculpado que haya sido citado o de su defensor (Ley de Organización de los Tribunales Ordinarios) y, de ese modo, no garantizar el derecho de defensa de los jueces de los tribunales ordinarios que hayan sido inculpados (para más detalles, vid. El ap. 3 del mencionado ATJ).

93 Ibidem, ap. 91-93. Para un análisis del Auto: L. PeCH, «Protecting Polish Judges from the Ruling Party's 'Star Chamber': The Court of Justice's interim relief order in Commission v Poland (Case C-791/19 R), Verfassungsblog, 9 April 2020.

94 «La protección de la independencia judicial...», op. cit., p. 26. Véase también M.J. García-VaLdeCASAS, «El Tribunal de Justicia, centinela...», op. cit., ap. IV

95 Por ejemplo, la petición de decisión prejudicial presentada el 17 de agosto de 2018 (Krajowa Rada, C-537/18); la remitida por el Tribunal Supremo de lo Contencioso-Administrativo (A.B. y otros, C-824/18), el 28 de diciembre de 2018; o la planteada por el Tribunal Supremo polaco (W.Z., C-487/19), el 20 de septiembre de 2019. 


\section{Hungría ${ }^{96}$; Rumania ${ }^{97}$; Alemania ${ }^{98}$; o la remitida, el 5 de diciembre de 2019, por el Tribunal Constitucional de Malta al TJ, en la que se plantea si deben considerarse aplicables los arts. 19.1(2) TUE y 47 de la CDFUE - conjuntamente o por}

96 Planteada el 24 de julio de 2019, en la que, en el marco de un proceso penal, el Tribunal remitente se plantea si el principio de independencia judicial recogido en el art. 19.1 (2), el art. 47 CDFUE y en la jurisprudencia del TJ debe interpretarse en el sentido de que «se vulnera dicho principio si el Presidente de la Oficina Nacional de la Judicatura, encargado de las funciones de administración central de los tribunales y nombrado por el Parlamento, que es el único ante el que debe rendir cuentas y que puede destituirlo, cubre el puesto de presidente de un tribunal — presidente que, entre otras, tiene facultades en materia de ordenación del reparto de asuntos, de incoación de procedimientos disciplinarios contra los jueces y de evaluación de estos últimosmediante designación directa temporal, eludiendo el procedimiento de convocatoria de candidaturas e ignorando permanentemente la opinión de los organismos competentes de autogobierno de los jueces» (IS, C-564/19).

97 Véanse, en este sentido, las Conclusiones del Abogado General Bobek, de 23 de septiembre de 2020, en los asuntos acumulados (que traen causa de diversas prejudiciales planteadas por Tribunales rumanos): C-83/19 Asociaţia «Forumul Judecătorilor Din România»/Inspecţia Judiciară, C-127/19 Asociaţia «Forumul Judecătorilor din România» y Asociația Mişcarea Pentru Apărarea Statutului Procurorilor/Consiliul Superior al Magistraturii, y C-195/19 PJ/QK, y en los asuntos C-291/19 SO/TP, y otros, C-355/19 Asociația «Forumul Judecătorilor din România» y Asociația «Mişcarea Pentru Apărarea Statutului Procurorilor» y OL/Parchetul de pe lângă Înalta Curte de Casaţie şi Justiţie - Procurorul General al României y C-397/19 AX/Statul Român - Ministerul Finanţelor Publice. Unas Conclusiones en las que el mencionado Abogado General entiende, entre otras cosas, que «son contrarios al Derecho de la Unión el nombramiento ad interlm del inspector jefe de la Inspección Judicial y las disposiciones nacionales sobre la constitución de una sección específica de la fiscalía con competencia exclusiva para investigar los delitos cometidos por magistrado».

98 Por ejemplo, la petición de decisión prejudicial presentada por el Tribunal de lo Contencioso-Administrativo de Wiesbaden, el 1 de abril de 2019 (VQ, C-272/19), en la que, a la postre, el propio tribunal remitente viene a cuestionarse si cumple o no con la exigencia de la independencia e imparcialidad, requisito necesario para ser considerado «órgano jurisdiccional» remitente conforme al artículo 267 TFUE, interpretado a la luz del artículo 47, párrafo segundo, de la Carta de los Derechos Fundamentales de la UE. Tal y como se describe en la reciente Sentencia emitida al respecto por el TJ, el 9 de julio de 2020, EU:C:2020:535 (ap. 44), esas dudas se refieren «a su propia independencia con respecto al poder legislativo o al poder ejecutivo», y se basan —en opinión del órgano jurisdiccional remitente- en que: «en primer lugar, los jueces son nombrados y promocionados por el Ministro de Justicia; en segundo lugar, la calificación de los jueces se regula por el Ministerio de Justicia con arreglo a las mismas disposiciones aplicables a los funcionarios; en tercer lugar, los datos personales y los datos de contacto profesionales de los jueces son gestionados por dicho Ministerio, que, de este modo, tiene acceso a esos datos; en cuarto lugar, para atender una necesidad temporal de personal, los funcionarios pueden ser nombrados jueces temporales, y, en quinto lugar, dicho Ministerio ordena la organización externa e interna de los órganos jurisdiccionales, establece la asignación de personal, los medios de comunicación y el equipo informático de los órganos jurisdiccionales y decide también los desplazamientos profesionales al extranjero de los jueces». Aplicando su jurisprudencia relativa al concepto de «órgano jurisdiccional» en el sentido del Derecho de la Unión, y en particular a la independencia exigida para poder ser considerado como tal, el Tribunal de Justicia declarará que los aspectos invocados por el Tribunal de Wiesbaden para apoyar sus dudas «no bastan, en sí mismos, para concluir que dicho tribunal no sea independiente» (ap. 60). El Tribunal de Luxemburgo recordará, asimismo, que el «el mero hecho de que los poderes legislativo o ejecutivo intervengan en el proceso de nombramiento de un juez no permite crear una dependencia entre aquellos y este ni generar dudas en cuanto a su imparcialidad, si, una vez nombrado, no está sometido a presión alguna y no recibe instrucciones en el ejercicio de sus funciones» (ap. 54; señalando al respecto su previa STJ A. K. y otros, cit., ap. 133). En línea con la anterior, se encuentra la remisión prejudicial planteada por el Tribunal Regional de Erfurt — 15 de junio de 2020 — en el marco del enjuiciamiento sobre el escándalo de VW, solicitando, entre otras cosas, aclaración acerca de si el propio tribunal remitente es independiente e imparcial en el sentido del art. 267 TFUE, 19.1(2) TUE y 47 de la Carta, dado que «la estructura del poder judicial, que data de tiempos predemocráticos, no proporciona obstáculos suficientes para la instrumentalización política». Sobre el tema: M. STEINBEIS, «Dieselrichter in Deutschland?», Verfassungsblog, Mo 22 Jun 2020. https://verfassungsblog.de/dieselrichter-in-deutschland/ 
separado-, a efectos de determinar la validez jurídica, entre otros, del artículo 96A de la Constitución de Malta (que entró en vigor tras la reforma constitucional de 2016), el cual establece la facultad del Primer Ministro en el proceso de nombramiento de los miembros de la judicatura de Malta ${ }^{99}$.

\section{Un apunte sobre las vías o mecanismos del control}

La casuística señalada en este trabajo permite constatar que las principales vías que se están utilizando para controlar las medidas nacionales opuestas a la tutela judicial efectiva reconocida en los arts. 19.1 (2) TUE y 47 CDFUE son la cuestión prejudicial y el recurso por incumplimiento. No es ahora el momento para extenderse en analizar a fondo las posibilidades y las limitaciones que, en lo que a nuestro tema se refiere, presentan ambos mecanismos. No obstante, es interesante apuntar muy brevemente varias consideraciones al respecto:

i) En primer lugar, que la misión del Tribunal de Justicia es, como él mismo ha recordado, «distinta según se le plantee una petición de decisión prejudicial o un recurso por incumplimiento». En la cuestión prejudicial (de interpretación) su tarea consiste en prestar asistencia al órgano remitente para que éste resuelva el litigio concreto del que conoce ${ }^{100}$. Pero en muchas ocasiones, como aquí, este instrumento se convierte en una herramienta para un control de eficacia o aplicabilidad del Derecho de la Unión (al hilo de las peticiones prejudiciales del Juez nacional $)^{101}$. Es sabido que el Tribunal de Luxemburgo no puede realizar un control sobre la legalidad de la actuación nacional; pero también es conocido que el Tribunal utiliza la remisión prejudicial como un procedimiento (indirecto) de control de la

99 El tribunal remitente pregunta, además, para el caso de que se determine que esa facultad del Primer Ministro es incompatible con el mencionado Derecho de la Unión, si ello debe incidir sobre nombramientos futuros o afectar asimismo a nombramientos pasados. Debe constatarse que el artículo en cuestión ha sido nuevamente reformado en julio de 2020.

100 STJ Miasto Eowicz, cit., ap. 47. Al respecto, véase también: P. Andrés Sáenz De Santa María, «Rule of Law and Judicial Independence...», op. cit., punto 1.2.3; «La protección de la independencia judicial...», op. cit., pp. 24-25.

101 Si bien es verdad que el mecanismo del artículo 267 TFUE no faculta al TJUE para aplicar las normas del Derecho de la UE a un asunto determinado, sino tan solo para interpretar los Tratados y los actos adoptados por las instituciones de la UE, también es cierto que, según reiterada jurisprudencia, el Tribunal de Justicia, en el marco de la cooperación judicial establecida en dicho artículo, puede proporcionar al órgano jurisdiccional nacional, a partir de los datos obrantes en los autos, los elementos de interpretación del Derecho del Unión que pudieran serle útiles para la apreciación de los efectos del mismo (ap. 132 STJ A.K. y otros, cit.). Y en esta línea, en virtud del principio de primacía, y en el supuesto de que no resulte posible interpretar la normativa nacional conforme a las exigencias del Derecho de la UE, el juez nacional encargado de aplicar, en el ámbito de su competencia, las disposiciones del Derecho de la Unión se encontrará ante la obligación de garantizar la plena eficacia de tales disposiciones, dejando inaplicada si fuera necesario, y por su propia iniciativa, cualquier disposición contraria de la legislación nacional, aun posterior, sin que deba solicitar o esperar su previa eliminación por vía legislativa o mediante cualquier otro procedimiento constitucional (ibidem, ap. 160). 
actividad normativa de los Estados miembros, cuando señala (o da a entender) que el Derecho de la Unión que se le pide interpretar «se opone» a determinada medida nacional.

Por su parte, la función del Tribunal de Justicia en el caso de un recurso por incumplimiento consiste en comprobar si la medida o la práctica nacional impugnada por la Comisión o por otro Estado miembro es, con carácter general (sin que sea necesario que se haya planteado el correspondiente litigio ante los órganos jurisdiccionales nacionales), contraria al Derecho de la Unión ${ }^{102}$. Es un control abstracto sobre el cumplimiento o no del Derecho de la Unión (de las obligaciones derivadas del mismo), no un control sobre su aplicabilidad o eficacia. Todo ello, sin perjuicio de que la declaración de incompatibilidad puede llegar a acarrear, de no corregirse, sanciones y/o multas coercitivas. En todo caso, la casuística manejada en este trabajo permite observar que el recurso por incumplimiento es un instrumento eficaz como mecanismo para controlar cualquier actuación o medida nacional que sea opuesta a la tutela judicial efectiva reconocida en los arts. 19.1 (2) TUE y 47 CDFUE y a las exigencias derivadas de la misma, como la independencia judicial ${ }^{103}$.

ii) Como segunda consideración es muy interesante no perder de vista que lo llamativo en el control de europeidad del que venimos hablando, sea éste activado por los jueces nacionales — cuestión prejudicial — o por la Comisión o los demás Estados miembros — recurso por incumplimiento-, no sólo reside en que el parámetro o estándar de control es el marcado por el Derecho de la Unión Europea (en nuestro caso, la tutela judicial efectiva según es reconocida en el Derecho de la Unión), sino que, además, esté control viene decidido por un órgano jurisdiccional supranacional: el Tribunal de Justicia. Tribunal que está operando, en la materia aquí tratada, en la línea de un tribunal constitucional federal, en el sentido de que actúa como el guardián del Estado de Derecho en el orden jurídico de la UE ${ }^{104}$

iii) Finalmente, debe apuntarse, asimismo, que existen todavía otros dos mecanismos o instrumentos interesantes de control, más allá del protagonismo

102 STJ Miasto Eowicz, cit., apdo. 47.

103 Se trata, además, como destaca M.J. García-VAldecasas ( El Tribunal de Justicia, centinela...», op. cit., ap. IV), de una vía que posibilita superar, entre otras cosas, los problemas que viene presentando la aplicación del mecanismo coactivo del art. 7 TUE, al que nos referiremos en breve, dando a la Comisión un camino «más rápido» que éste para solucionar los problemas relativos al Estado de Derecho en lo que se refiere a la independencia judicial. Véanse, también, sobre el tema: J.M. CorTÉs MARTín, «Sorteando los inconvenientes del artículo 7 TUE...», op. cit., pp. 479 y ss., A. KRZYWON, «La defensa y el desarrollo del principio de independencia judicial en la Unión Europea», REDC, 119, 2020, especialmente pp. 89 y ss.

104 Cfr: P. VAN Elsuwege y F. Gremmelprez, «Protecting the Rule of Law in the EU Legal Order...», op. cit., p. 10. Dichos autores observan una tendencia en la jurisprudencia del Tribunal en la que el artículo 2 TUE es utilizado, en combinación con el Artículo 19 TUE, como un punto de referencia crucial para fortalecer su papel constitucional. 
de la cuestión prejudicial y el recurso por incumplimiento. Ahí están, de un lado, las medidas provisionales del art. 279 TFUE, a las que el Tribunal está dando, como se ha podido observar, un papel significativo en el control de las medidas nacionales polacas de las que venimos hablando ${ }^{105}$.

De otro lado, nos encontramos, asimismo, con la vía coercitiva (para situaciones límite) del art. $7 \mathrm{TUE}^{106}$. Como es sabido, dicho artículo configura dos mecanismos, ambos destinados a la tutela coactiva de los valores reconocidos en el art. 2 del TUE, incluido el Estado de Derecho. Un mecanismo es de carácter preventivo, para el caso de la existencia de un riesgo claro de violación grave por parte de un Estado miembro; y otro de carácter sancionatorio, para cuando se constate una violación grave y persistente. Las consecuencias del control varían en un caso y en otro. Pero no se trata de un control de legalidad, sino de uno de naturaleza y efectos políticos, para el caso de riesgos sistémicos respecto a la vulneración de los mencionados valores. Y donde los protagonistas del control son todos ellos actores no internos o nacionales, supraestatales (Comisión europea, Parlamento Europeo, Consejo Europeo, etc.) y, además, no jurisdiccionales.

Este mecanismo ha sido ya activado — en su vertiente preventiva— por la Comisión contra Polonia (2017), por generar un riesgo claro de violación del valor Estado de Derecho ${ }^{107}$; y el Parlamento europeo la puso en marcha en relación con Hungría (2018), debido al riego claro de violación grave de

105 Sobre el uso del procedimiento de medidas provisionales como instrumento para garantizar el respeto del Estado de Derecho: P. Van Elsuwege y F. Gremmelprez, «Protecting the Rule of Law in the EU Legal Order...», op. cit., pp. 20-22.

106 Analizando otros instrumentos o vías que ayudan también, de una u otra forma, en la defensa y promoción de la independencia judicial, la tutela judicial efectiva y el Estado de Derecho: R. Bustos GisBERT, «Comunicación transjudicial en Europa...», op. cit.

107 Una vez planteadas previamente una serie de recomendaciones acerca de la independencia del Poder Judicial, la Comisión presentó, el 20 de diciembre de 2017, la Propuesta [motivada de conformidad con el art. 7.1 TUE por lo que respecta al Estado de Derecho en Polonia] de Decisión del Consejo relativa a la constatación de un riesgo claro de violación grave del Estado de Derecho por parte de la República de Polonia: [2017] [COM(2017) 835 final]. Como es conocido, la Comisión, ya había puesto en marcha en 2014 el llamado «Marco de la UE para reforzar el Estado de Derecho» [Comunicación de la Comisión al Parlamento Europeo y al Consejo: Un nuevo marco de la UE para reforzar el Estado de Derecho (COM/2014/0158 final)], y en julio de 2019 dio un paso más en esta línea de defensa con la Comunicación de la Comisión al Parlamento Europeo, al Consejo Europeo, al Consejo, al Comité Económico y Social Europeo y al Comité de las Regiones: Refuerzo del Estado de Derecho en la Unión. Propuesta de actuación [COM (2019) 343 final]. Además, presentó, en mayo de 2018, una Propuesta de Reglamento del Parlamento Europeo y del Consejo sobre la protección del presupuesto de la Unión en caso de deficiencias generalizadas del Estado de Derecho en los Estados miembros [COM/2018/324 final], propuesta en la que la financiación quedaba vinculada al respeto del Estado de Derecho. Por lo demás, la cumbre de Jefes de Estado y de Gobierno de julio de 2020 relativa al fondo de recuperación de la UE ha acordado, entre otras cosas, establecer también un vínculo entre las ayudas pospandemia de COVID-19 y el respeto del Estado de Derecho de la Unión. Así puede entenderse a tenor del acuerdo adoptado acerca de que la Comisión Europea deberá elaborar un «régimen de condicionalidad» que incluya la observancia de principios constitucionales —entre los que se encuentra el respeto del Estado de Derecho- y que, en caso de que esas condiciones sean infringidas, dicha institución podrá «imponer medidas sancionatorias que deban ser confirmadas por la mayoría de Consejo». 
los valores en los que se fundamenta la Unión ${ }^{108}$. No obstante, debe destacarse, en honor a la verdad, que este mecanismo está mostrando serios problemas o limitaciones en cuanto a su aplicación. Unos problemas que llevan a concluir, como hace el profesor Dimitry Kochenov, que la finalidad de este artículo parece consistir en incentivar a los Estados miembros concernidos a empezar un diálogo con las instituciones de la Unión al efecto de evitar una posible infracción ${ }^{109}$.

\section{CONCLUSIONES}

En la medida en que el Juez nacional es también Juez de la Unión Europea, el Derecho de la Unión debe velar porque su función jurisdiccional —consistente, también, en garantizar la plena aplicación del Derecho de la Uniónpueda ser desarrollada conforme a las exigencias del derecho fundamental a la tutela judicial y al valor Estado de Derecho reconocidos en la Unión [arts. 19.1(2) TUE, 47 Carta DFUE y art. 2 TUE]. De la jurisprudencia del TJ se deduce que el respeto de la independencia judicial — según estándares europeos — es una exigencia primordial en este sentido. Desde hace dos años, el Tribunal está reconociendo y fortaleciendo la existencia de esa dimensión objetiva o estructural de la tutela judicial efectiva reconocida en la UE. Una que no se limita a asegurar la existencia de un derecho subjetivo a la protección judicial, sino que protege también su dimensión sistémica o constitucional, sin la cual no existiría el Estado de Derecho. El Derecho nacional contrario a la misma y a sus exigencias, incluida la regulación relativa a la Administración de Justicia, no puede ser operativo o eficaz en la Unión.

De cualquier manera, esta defensa de la dimensión sistémica o estructural de la tutela judicial, que es, en cierto modo, una reacción frente al proceso de «retroceso del Estado de Derecho» (rule of law backsliding) que se está produciendo en algunos países de la Unión ${ }^{110}$, no sólo tiene como fin la protección del Estado de

108 Resolución del Parlamento Europeo, de 12 de septiembre de 2018, sobre una propuesta en la que solicita al Consejo que, de conformidad con el artículo 7, apartado 1, del Tratado de la Unión Europea, constate la existencia de un riesgo claro de violación grave por parte de Hungría de los valores en los que se fundamenta la Unión [2017/2131(INL)].

109 «Article 7: A Commentary on a Much Talked-About 'Dead' Provision», University of Groningen, Faculty of Law, Research Paper Series, 2019, 21. https://papers.ssrn.com/sol3/papers.cfm?abstract_id=3380042\#\#

$110 \mathrm{Un}$ «proceso mediante el cual las autoridades públicas elegidas implementan deliberadamente proyectos gubernamentales que tienen como objetivo debilitar, aniquilar o capturar sistemáticamente controles internos del poder con el objetivo de desmantelar el estado democrático liberal y afianzar el gobierno a largo plazo del partido dominante» (L. PECH and K.L. SCHeppele, «Illiberalism Within: Rule of Law Backsliding in the EU», Cambridge Yearbook of European Legal Studiesm, 19, 2017, pp. 3 y ss., espec. 10 y ss.; sobre el tema también, entre otros: J. Martín y PÉrez De NAnClares, «La Unión Europea como comunidad de valores: a vueltas con crisis de la Democracia y del Estado de Derecho», TRC, 43, 2019, pp. 121 y ss.; D. Kochenov, «The Last Soldier Standing? Courts vs. Politicians and the Rule of Law Crisis in the New Member States of the EU», University of Groningen Faculty of Law Research Paper Series, 2019, 5; o V. FAGGIANI «La 
Derecho. El Tribunal también desliza no pocas veces entre sus argumentos la trascendencia que todo ello tiene, a su vez, en la protección de la eficacia del Derecho de la Unión y en el respeto de los otros valores y los objetivos de la Unión, así como para la existencia de un espacio común sin fronteras basado en esa comunidad de valores y derechos. En otras palabras, en este "partido» no solo está en juego la existencia del Estado de Derecho en la Unión y sus Estados miembros, sino que lo está también, con ello, el proyecto de la propia Unión.

El Tribunal de Justicia ha venido a reconocer efecto a esa dimensión objetiva o estructural de la tutela judicial ante la normativa nacional relativa a la Administración de Justicia opuesta a la misma, aun siendo esta materia de exclusiva competencia estatal. Y lo ha hecho basándose en el parámetro o estándar de la tutela judicial de la Unión. Además, los mecanismos mediante los que se está vehiculando principalmente el control de europeidad frente a esas medidas nacionales eventualmente contrarias son la cuestión prejudicial y el recurso por incumplimiento. Los jueces nacionales juegan un papel fundamental en el primero y la Comisión en el segundo. Pero quien tiene el peso decisorio es el Tribunal de Justicia, una institución supraestatal. No hay duda de que la concepción europea del Estado de Derecho ha sido incorporada a la configuración de la Administración de Justicia nacional.

\section{$* * *$}

TITLE: Effective judicial protection and the rule of law in the EU and their impact on the administration of justice in the Member States

ABSTRACT: The recognition of effective judicial protection under European Union law affects national regulations on the administration of justice. There is no doubt that the competence to regulate and act upon matters relating to the organisation and functioning of the national judiciary is an exclusively State competence, not transferred by the States. However, over the last couple of years, the Court of Justice has been implying that national measures concerning the national administration of justice cannot be contrary to the regulations on judicial protection as recognised by the Union. This European regulation works as a limit to those national measures relating to the administration of justice, making it possible to review their "Europeanness». These pages show on which legal bases, in which cases and with which mechanisms this review is taking place.

RESUMEN: El reconocimiento de la tutela judicial efectiva que realiza el Derecho de la Unión Europea incide sobre la regulación nacional de la Administración de Justicia. No cabe duda de que la competencia para regular y actuar en materia relativa a la organización y funcionamiento judicial nacional es una competencia exclusivamente estatal, no transferida por los Estados. Sin embargo, desde hace un par de años, el Tribunal de Justicia está dando a entender que las medidas nacionales sobre la Administración judicial nacional no pueden ser contrarias a la regulación sobre la tutela o protección judicial tal y como ésta es reconocida por la Unión. Esta regulación europea actúa como límite de esas medidas nacionales relativas a la Administración de Justicia, posibilitando un control de europeidad de las mismas. Estas páginas muestran sobre qué bases jurídicas, en qué casos y con qué mecanismos se está dando este control de europeidad.

'rule of law backsliding' como categoría interpretativa del declive del constitucionalismo en la UE», REDE, 71,2019 , pp. 57 y ss.). 
KEY WORDS: Effective legal protection (article 19 TEU); right to an effective remedy (article 47 CFREU); rule of law; judicial independence.

Palabras Clave: Tutela judicial efectiva (artículo 19 TUE); derecho a la tutela judicial efectiva (artículo 47 CDFUE); Estado de Derecho; independencia judicial.

FECHA DE RECEPCIÓN: 17.06.2020

FECHA DE ACEPTACIÓN: 09.09.2020 
